\title{
Site-Directed Mutagenesis in the Research of Protein Kinases - The Case of Protein Kinase CK2
}

\author{
Ewa Sajnaga, Ryszard Szyszka and Konrad Kubiński \\ Department of Molecular Biology, Institute of Biotechnology, \\ The John Paul II Catholic University of Lublin, \\ Poland
}

\section{Introduction}

Protein kinases constitute one of the largest and best-explored superfamilies of mammalian genes. The human genome encodes approximately 518 protein kinase genes, and the majority of their proteins have been characterized to some extent. Many of protein kinases have been implicated in signal transduction pathways that regulate growth and survival of cells, indicating their potential role in cancer (Manning et al., 2002a). Indeed, most cancers are associated with disregulation of protein kinases or by loss or damage of cellular protein kinase inhibitors (Brognard \& Hunter, 2011; Johnson, 2009; Pearson \& Fabbro, 2004).

A typical protein kinase (based on 478 known enzymes) is characterized by the presence of a highly homologous kinase catalytic domain of about 300 amino acid residues. This domain serves three distinct roles: (a) binding and orientation of the phosphate donor (ATP or, rarely, a different nucleoside triphosphate) in a complex with a divalent cation (usually $\mathrm{Mg}^{2+}$ or $\mathrm{Mn}^{2+}$ ); (b) binding and orientation of the protein substrate; and (c) transfer of the $\gamma^{-}$ phosphate from the NTP to the hydroxyl moiety of the acceptor residue of the protein substrate.

In response to a variety of regulatory signals, protein kinases phosphorylate specific serine, threonine, or tyrosine residues within target proteins to modify their biological activities. Phosphorylation of several proteins in the cell creates recognition and/or regulatory sites that influence many properties of the target proteins (e.g., catalytic activity, localization, sensitivity to proteolytic degradation, protein-protein interaction, etc). In eukaryotes, Ser/Thr and Tyr protein kinases (Note: The single- and three-letter codes for the amino acids are given in Table 1 in the chapter by Figurski et al.) play a key role in molecular networks controlling the activity of various signaling proteins (Brognard \& Hunter, 2011; Cohen, 2002). Ser/Thr and Tyr-protein kinases form the largest protein family in the human genome (Pandit et al., 2004). They constitute about 2-3\% of the proteomes of other model organisms, such as Saccharomyces cerevisiae, Caenorhabditis elegans and Drosophila melanogaster (Manning et al., 2002 a, b; Goldberg et al., 2006; Plowman et al., 1999). Based on the conserved features of catalytic domains of eukaryotic protein kinases, Hanks and coworkers have placed the kinases into various classes, groups, and subfamilies (Hanks et al., 1988). 
The first 3D structure of a protein kinase was determined for PKA by X-ray crystallography. It revealed the basic bi-lobed scaffold formed by $\mathrm{N}$ - and $\mathrm{C}$-terminal lobes that has been observed in all the protein kinase structures solved to date. The N-terminal lobe of the kinase fold comprises of an anti-parallel $\beta$-sheet made of five $\beta$-strands $(\beta 1-\beta 5)$ and a single aC-helix. The C-terminal lobe is larger and is mainly composed of a-helices. The nucleotide- and substrate-binding pockets are located in the cleft between the two lobes. The phosphate groups of ATP are positioned for phosphotransfer by their interactions with conserved residues in the $\mathrm{N}$ - and C-terminal lobes. These include a glycine-rich loop characterized by the GXGXXG motif (where $X$ represents any amino acid) between the $\beta 1$ and $\beta 2$ strands, a Lys residue localized by a salt bridge formed by a Lys-Glu pair (K72 and E91), and $\mathrm{Mg}^{2+}$ ions. The conserved Asn (N171) and Asp (D184) further coordinate the metal ions. The catalytic loop situated in the C-terminal lobe contains aspartate (D166), referred to as the catalytic base that facilitates extraction of a proton from the hydroxyl side-chains of the phospho-sites of the substrates. The activation segment (20-30 residues in length) caps the C-terminal lobe. This segment forms a part of the substrate-binding pocket and shows high structural variation in the active and inactive kinase structures.

The grouping of the protein kinases based on catalytic subunit sequence similarity results in clustering of kinases that share functional features, such as preferred sites of phosphorylation, the mode of regulation and cellular localization. The similarity in the amino acid sequence of the catalytic domains of protein kinases has proven to be a good indicator of other features held in common by the different members of the family.

The diversity of essential functions mediated by kinases is shown by the conservation of approximately 50 distinct kinase families that have been identified in yeast, invertebrates, and mammals. Protein kinases can be clustered into groups, families, and sub-families. These classifications are based on sequence similarity and biochemical function. Among the 518 human protein kinases, 478 belong to a single superfamily whose catalytic domains are related in sequence.

Protein kinases are divided into 10 main groups, which organize diversity and compare genes between distant organisms (Miranda-Saavedra \& Barton, 2007). The groups are named as follows: AGC, CAMK, CK1, CMGC, STE, RGC, Other, TK, TK, and Atypical. This classification was first used for characterization of the human kinome (all the kinases encoded in the genome) (Manning et al., 2002) and is based on an earlier classification by Hanks and Hunter (1995).

\subsection{The CMGC kinases}

This group of Ser/Thr protein kinases was named after the initials of some members (CDK, MAPK, GSK3, and CLK). It includes key kinases involved in growth, stress-response, and the cell cycle, and kinases involved in splicing and metabolic control. The four well characterized subfamilies of this group include the following: cyclin-dependent kinases (CDK) (Liolli, 2010); mitogen-activated protein kinases (MAPK) (Biondi \& Nebreda, 2003; Zhang \& Dong, 2007); glycogen synthase kinases (GSK) (Biondi \& Nebreda, 2003); and cell kinases 2 (CK2), better known as protein kinase CK2 or casein kinase 2 (St-Denis \& Litchfield, 2009). The CMGC group also contains other members. These are the following: SR protein kinases [phosphorylating serine- and arginine-rich proteins engaged in regulation of splicing and nuclear transport (Ghosh \& Adams, 2011)] and DYRK protein 
kinases, i.e. dual-specificity tyrosine-phosphorylated protein kinases, presumably involved in brain development (Becker et al., 1998).

\subsection{Protein kinase CK2}

Protein kinase CK2, formerly called casein kinase II, is a ubiquitous second messengerindependent protein kinase found in all eukaryotic organisms examined (Jensen et al., 2007; Niefind et al., 2009; Litchfield, 2003, Kubiński et al., 2007). This enzyme, which has been studied for over 50 years, is able to phosphorylate more than 300 substrates, on serine, threonine and tyrosine (Meggio \& Pinna, 2003; Vilk et al., 2008). As the list of targets for CK2 continues to grow, it is becoming evident that CK2 has the potential to participate in the regulation of various cellular processes. Most of the CK2 substrates reported so far correspond to proteins that participate in cell signaling (Ahmed et al., 2002; Meggio \& Pinna, 2003).

CK2 $\alpha$

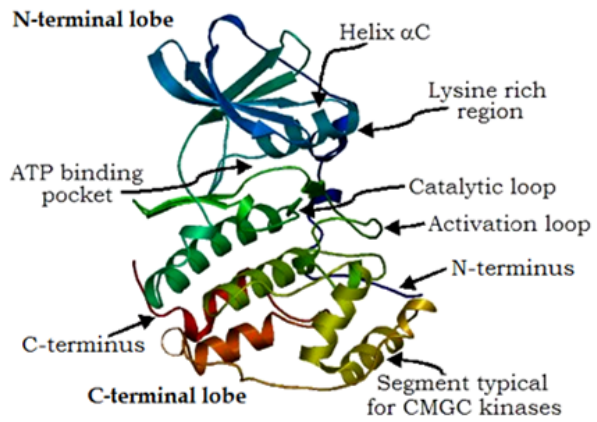

CK2 $\beta$

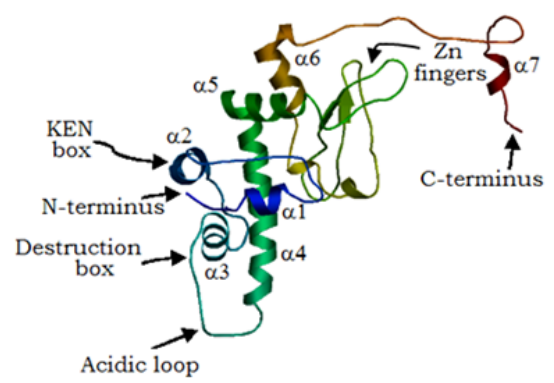

Fig. 1. Model structures of the CK2 $\alpha$ and CK2 $\beta$ subunits from Mytilus galloprovincialis (Mediterranean mussel) (Koyanou-Koutsokou et al., 2011b)

The structural features of the CK2 $a$ and CK2 $\beta$ subunits were elaborated using the SWISS-MODEL Workspace for protein structure homology modeling (Arnold et al., 2006; Kopp and Schwede 2004) and 1ds5D (Batistuta et al., 2000) or 3EED (Raaf et al., 2008) as templates, respectively.

Protein kinase CK2 is distributed ubiquitously in eukaryotic organisms, where it appears as a tetrameric complex composed of two catalytic subunits $\left(\alpha / \alpha^{\prime}\right)$ associated with a dimer of regulatory $\beta$ subunits (Figs. $1 \& 2$ ). The CK2 tetramer exhibits constitutive activity that can be easily detected in most cellular or tissue extracts in the absence of any stimulatory compounds. In many organisms, distinct isoenzymic forms of the catalytic subunit of CK2 have been identified (Glover, 1998; Kolaiti et al., 2011; Kouyanou-Koutsoukou et al., 2011a, b; Maridor et al., 1991; Litchfield et al., 1990; Shi et al., 2001). In humans, only a single regulatory $\mathrm{CK} 2 \beta$ subunit has been identified; but multiple forms of $\mathrm{CK} 2 \beta$ have been identified in other organisms, such as Saccharomyces cerevisiae (Glover, 1998). Complementary evidence indicates that dimers of CK2 $\beta$ are at the core of the tetrameric CK2 complexes (Graham \& Litchfield, 2000; Pinna \& Meggio, 1997). Tetrameric CK2 complexes may contain identical (i.e., $\alpha_{2} \beta_{2}$ or $\alpha_{2}^{\prime} \beta_{2}$ ) or non-identical (i.e., $a \alpha^{\prime} \beta_{2}$ ) catalytic subunits (Gietz et al., 1995). Holoenzyme composition may influence CK2 properties, namely nucleotide and protein substrate specificity and sensitivity to effectors (Janeczko et 
al., 2011). Protein kinase CK2 holoenzyme and its catalytic subunit alone can use both ATP and GTP as phosphate donors (Issinger, 1993).

The catalytic subunits of CK2a and CK2 $\alpha^{\prime}$ are the products of separate genes located in different chromosomes. The $330 \mathrm{~N}$-terminal amino acids exhibit over $90 \%$ sequence identity. However, the C-terminal sequences are unrelated (Olsten \& Litchfield, 2004). The unique Cterminal domains of the catalytic subunits are highly conserved among species (e.g., the amino acid sequences of the C-termini of the catalytic subunits of human and chicken CK2a and CK2 $a^{\prime}$ exhibit $98 \%$ and $97 \%$ identity, respectively), indicating a possible functional importance for this domain (Litchfield, 2003).

Although there is no known difference between the catalytic activities of CK2 $a$ and CK2 $\alpha^{\prime}$, there is evidence that they exhibit functional specialization (Duncan \& Lichfield, 2008; Faust \& Montenarch, 2000). The CK2 $\alpha$ subunit is phosphorylated at C-terminal sites (Thr344, Thr360, Ser362 and Ser360) by p34cdc2 during cell cycle progression, while CK2 $\alpha^{\prime}$ is not phosphorylated (St-Denis et al., 2009). Further evidence to support the idea that CK2a and CK2 $a^{\prime}$ have independent functions in the cell is provided by the different specificities of cellular binding proteins, such as CKIP-1, Hsp90, Pin-1, and PP2A (Olsten et al., 2005).

Despite the many isoforms of catalytic subunits, only one regulatory subunit has been identified for CK2 $\beta$ in mammals (Allende and Allende, 1995). In contrast to the activity of regulatory subunits of other kinases, such as PKA (cAMP-dependent protein kinase) and CDK (cyclin-dependent protein kinase), CK2 $\beta$ does not switch on or off the intrinsic activity of the catalytic subunits (Bolanos-Garcia et al., 2006).

The CK2 $\beta$ regulatory subunit is remarkably conserved among species, but it does not have homology with the regulatory subunits of other protein kinases (Bibby \& Litchfield, 2005). The amino acid sequence of the CK2 $\beta$ regulatory subunit is almost identical in Homo sapiens, Drosophila melanogaster, Ceratitis capitata (Mediterranean fruit fly), Danio rerio (zebrafish), Ciona intestinalis (sea squirt), and Mytilus galloprovincialis (Mediterranean mussel) (Kouyanou-Koutsoukou et al., 2011a, b; Kolaiti et al., 2011). It is completely identical in birds and mammals (Maridor et al., 1991; Wirkner et al., 1994). In contrast, the fruit fly D. melanogaster has four regulatory subunit genes. They are used for one CK2 $\alpha$ (DmCK2 $\alpha$ ) and three CK2 $\beta$ s (DmCK2 $\beta$, DmCK2 $\beta$ ' and DmCK2 $\beta$ tes) (Jauch et al., 2002). Zea mays has three isoforms of the catalytic a-subunit (CK2a-1, CK2a-2 and CK2a-3) and three regulatory $\beta$ subunits (CK2b-1, CK2b-2 and CK2b-3) (Riera et al., 2001). S. cerevisiae CK2 holoenzyme contains two regulatory $\beta$-subunits $\left(\beta\right.$ and $\left.\beta^{\prime}\right)$. They cannot substitute for each other, and both of them are needed to form a fully active enzymatic unit (Kubinski et al., 2007).

Results presented by several groups and obtained by the use of a variety of approaches, including X-ray crystallography, have determined that a dimer of the CK2 $\beta$ subunits forms the core of the CK2 tetramer (Chantalat et al., 1999; Sarno et al., 2000; Canton et al., 2001).

The CK2 $\beta$ regulatory subunit is a compact, globular homodimer that shows high amino acid sequence conservation across species. The N-terminal domain (amino acids 1-104) is globular and contains four a-helices (marked as a1-a4 in Fig. 1). Helices a1 (residues 9-14), a2 (residues 27-31) and a3 (residues 46-54) wrap around a4 (residues 66-89) (BolanosGarcia et al., 2006). This part of the protein contains autophosphorylation sites, consisting of serines 2, 3, and possibly 4 (Boldyreff et al., 1993). Studies conducted by Zhang and coworkers (2002) indicate that phosphorylation of these sites enhances CK2 $\beta$ stability. The 
first $20 \mathrm{~N}$-terminal amino acids of the CK2 $\beta$ regulatory subunit are also involved in the interaction with Nopp140, a protein that binds a nuclear localization sequence and shuttles between the nucleus and the cytoplasm ( $\mathrm{Li}$ et al., 1997). This part of the protein also contains two motifs that have been previously characterized as motifs that regulate cyclin degradation. The CK2 $\beta$ regulatory subunit has a sequence resembling the nine-amino-acid motif called the destruction box, which plays a key role in the specific degradation of cyclin $\mathrm{B}$ at the end of mitosis (King et al., 1996). This motif, located in helix a3, contains three highly conserved residues that conform to the general destruction box consensus (RXXLXXXXN/D) (Bolanos-Garcia et al., 2006). Interestingly, this motif is located on a surface-exposed a3 helix, where it would be available for recognition by the cellular degradation machinery. A signal known as the KEN box, which was found previously in mitotic cyclins and which has been shown to play a role in mediating cell cycle-dependent protein degradation, is also present in CK2 $\beta$. This degradation motif is characterized by the minimal consensus sequence KEN, but it is often followed shortly by either an $\mathrm{N}$ or $\mathrm{D}$ residue and is often preceded by another $\mathrm{N}$ or $\mathrm{D}$ residue. $\mathrm{A}$ similar sequence $\left(D_{32} K_{F N L T G L N}^{40}\right)$ forms helix $\alpha 2$ of the CK2 $\beta$ protein (Bibby \& Litchfield, 2005).

The N-terminal part of the CK2 $\beta$ also contains an "acidic loop" between helices a 3 and $\alpha 4$. This acidic, surface-exposed region of the protein, encoded by residues 55-64, has been identified as the site on CK2 that binds polyamines, which are known to stimulate CK2 activity in vitro (Meggio et al., 1994; Leroy et al., 1997).

The analysis of the CK2 $\beta$ regulatory subunit structure by $X$-ray crystallography revealed the importance of the zinc finger in CK2 $\beta$ regulatory subunit dimerization (Chantal et al., 1999). The zinc-finger region is characterized by four conserved cysteine residues (residues 109, 114,137 and 140), which mediate the interaction that allows the CK2 $\beta$ dimer to form the core of the CK2 holoenzyme (Chantal et al., 1999; Canton et al., 2001).

The C-terminal part of the CK2 $\beta$ regulatory subunit (residues 178-205) contains a large loop (residues 178-193) and helix $\alpha 7$ (residues 194-200). Although helix $\alpha 7$ is located away from helices a1-a6, the C-terminal amino acids (190-205) contribute to the formation of the CK2 $\beta$ regulatory subunit dimer (Niefind et al., 2001). This part of the regulatory subunit contains two phosphorylation sites: Thr213, which is phosphorylated by the checkpoint kinase Chk1 (Kristensen et al., 2004) and Ser209, which is phosphorylated in vitro and in mammalian cells by p34cdc2 in a cell-cycle-dependent manner (Litchfield et al., 1995).

The traditional view of the CK2 $\beta$ regulatory subunit is that it functions as a component of tetrameric CK2 complexes and that it is the regulator of the catalytic CK2 $\alpha$ and CK2 $\alpha^{\prime}$ subunits, enhancing their stability, specificity and activity. As an example, the CK2 $\beta$ regulatory subunit stimulates CK2 holoenzyme activity towards certain protein substrates, such as topoisomerase II (Leroy et al., 1999), and inhibits others, like calmodulin (Marin et al., 1999).

It was shown that CK2 $\beta$ does not exist exclusively within stable CK2 complexes. This observation raises the prospect that $\mathrm{CK} 2 \beta$ has functions that are independent of its role as the regulatory subunit of CK2. For example, overexpression of CK2 $\beta$ in the fission yeast Schizosaccharomyces pombe revealed severe growth defects and a multiseptated phenotype, whereas CK2a overexpression had no effect (Roussou \& Draetta, 1994). 
CK2 $\beta$ seems to interact directly with more than 40 different proteins, including other protein

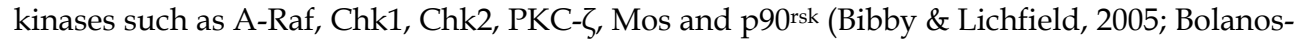
Garcia et al., 2006; Olsen \& Guerra, 2008). It was shown that association of the human protein kinases Chk1, Mos, and A-Raf is mediated by the C-terminal region of the CK2 $\beta$ subunit and that these associations involve some residues that interact with the catalytic CK2a subunit (Chen et al., 1997; Lieberman \& Ruderman, 2004; Olsen \& Guerra, 2008). The interaction between Chk1 and CK2 $\beta$ leads to an increase in the Cdc25C phosphorylation activity of Chk1. Screening of several cell lines has shown that the association between CK2 $\beta$ and Chk1 is also formed in vivo (Guerra at al., 2003).

Overexpression of CK2 has been linked to several pathological conditions, ranging from cardiovascular pathologies and cancer progression to neurodegenerative disorders (e.g., Alzheimer's disease, Parkinson's disease, brain ischemia) and infectious diseases (Guerra \& Issinger, 2008; Ahmad et al., 2008; Trembley et al., 2009). Various specific, potent small molecule inhibitors of protein kinase CK2 have been developed in recent years, including condensed polyphenolic compounds, tetrabromobenzimidazole/triazole derivatives, and indoloquinazolines (Gianoncelli et al., 2009; Pagano et al., 2008; Raaf et al., 2008). Inhibition of CK2 kinase activity by these compounds display a remarkable pro-apoptotic efficacy on a number of tumor-derived cell lines, indicating a possibility of developing novel antineoplastic drugs (Batistuta, 2009; Duncan et al., 2010; Prudent et al., 2010; Unger et al., 2004).

\section{Mutagenesis in studies on protein kinase CK2}

Within the last 2 decades, a number of studies have produced mutants of both CK2a and CK2 $\beta$ that provide a valuable, yet incomplete, basis to rationalize the biochemical features of the enzyme, i.e., its constitutive activity, dual-cosubstrate specificity, acidophilic substrate specificity and tetrameric structure (Fig. 2).

\subsection{Mutagenesis of the CK2 $\alpha$ catalytic subunit}

\subsubsection{Mutations of CK2 $\alpha$ in the regions responsible for constitutive activity}

A majority of protein kinases need to be activated. Phosphorylation within the kinase activation loop is the most popular mode of activation. In contrast to other known protein kinases, CK2 has constitutive activity and does not demand activation. In this case, activation is achieved by the interaction between the N-terminal tail and the activation loop in the kinase domain. The role of the N-terminal segment in stable opening of the activation loop was confirmed in mutagenesis studies (Sarno et al., 2001). In particular, the $\Delta 2-12 C K 2 a$ mutant, in comparison with the wild-type kinase, displayed an almost complete loss of activity, which was reflected by increased $\mathrm{Km}$ values for ATP and the peptide substrate (from 10 to $206 \mu \mathrm{M}$ and from 26 to $140 \mu \mathrm{M}$, respectively). Further experiments revealed that holoenzyme reconstitution restored the activity of the mutant to the wild-type level. This demonstrates an alternative CK2 $\beta$ subunit-dependent mechanism to provide constitutive activity in the case of CK2 holoenzyme (Sarno et al., 2002).

Recently, molecular dynamics (MD) simulation has been carried out in order to explore the role of the CK2a N-terminal segment in the conformational behavior of the kinase (Cristiani 


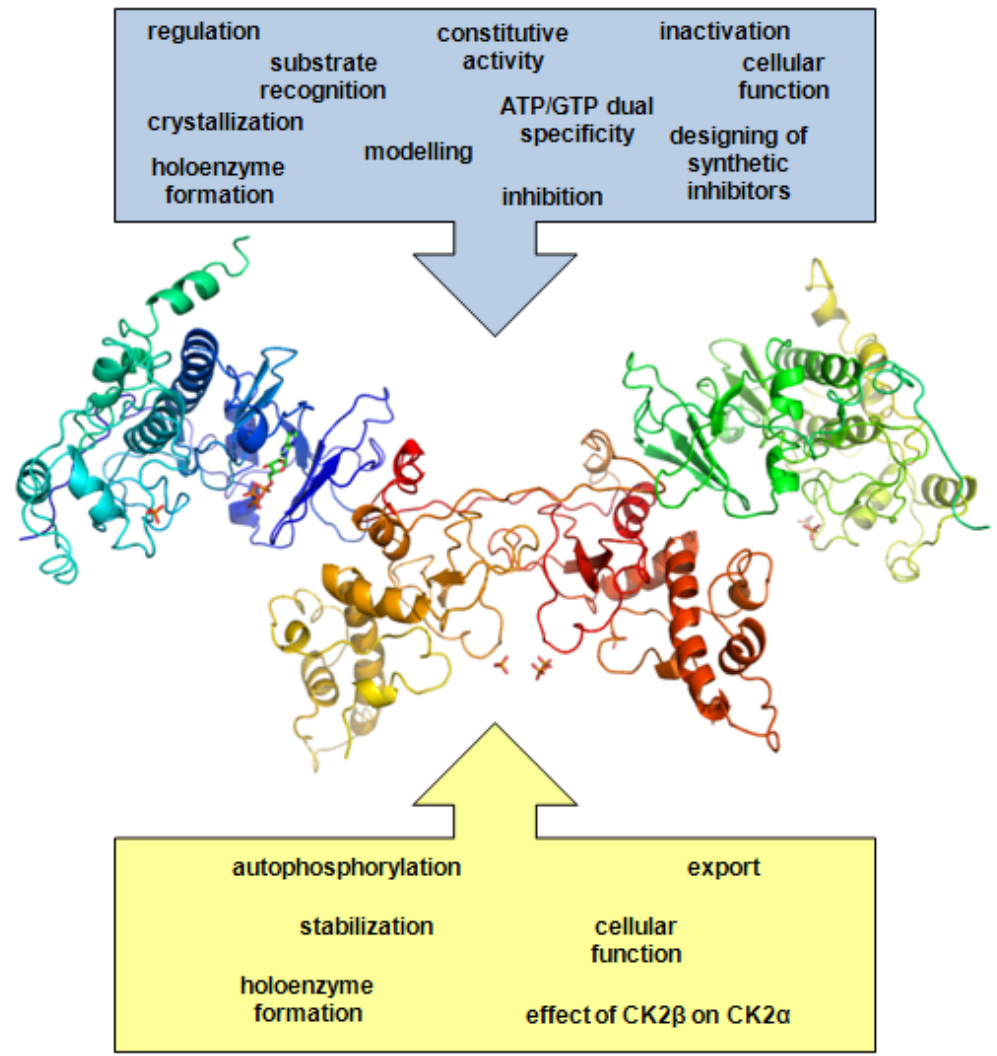

Fig. 2. Multiple applications of mutagenesis in studies on CK2.

The blue box presents various aspects of research using mutagenesis on CK2a; and the yellow box, on CK2 $\beta$. The model of the human CK2 holoenzyme was developed using the PyMOL software based on the structure of the human CK2 holoenzyme (PDB code 1JWH) from the Protein Data Bank. The catalytic a subunits are presented in blue and green; the regulatory $\beta$ subunits are in red and yellow.

et al., 2011). Comparison of the aC-helix RMSD (root mean square deviation) values obtained for the $\Delta 2-12$ CK2a mutant (i.e., deleted for residues 2 through 12) and the wildtype kinase models show an increase in this parameter for the mutant form of the enzyme. This effect is due to instability of the CK2a conformation in the case of absence of an Nterminal segment and its interaction with the aC-helix. These results are consistent with the data presented by Sarno and collaborators, and they indicate that the complete N-terminal segment is essential for proper conformation and constitutive activity of protein kinase CK2a (Cristiani et al., 2011).

The experiment presented above is an example of the validation of in vitro mutagenesis studies with the use of computing analysis, but the opposite direction of studies is also possible. Two CK2a mutants, the triple mutant Y206F/R10A/Y261F and the single mutant Y125F, were constructed in silico. MD simulations were then carried out to study the relation 
between CK2 conformation and activity (Cristiani et al., 2011). The amino acids substituted in the first virtual mutant are engaged in the most important bonds between the $\mathrm{N}$-terminal segment and other regions of CK2 $\alpha$ to maintain kinase activity. The CK2 $\alpha$ Y125F mutant is also very useful in studying the influence of Tyr125 on the conformational change of Phe121. According to Niefind and Issinger (2010), Phe121 can assume two different conformations: in and out, which regulate the activity of CK2a. Preliminary MD simulations on the two protein mutant models are very promising. The authors are currently working on the construction of both CK2 mutants. Biochemical characterization of the mutants will be carried out (Cristiani et al., 2011).

\subsubsection{Mutation of CK2 $\alpha$ in the basic regions}

Protein kinase CK2 is characterized by its special aptitude to interact with negatively charged ligands. This ability correlates with the presence of several basic residues in CK2a that are not conserved in a majority of other protein kinases. These residues are located mainly in the "Lys-rich segment" and in the "p+1 loop." The Lys-rich segment $\left(\mathrm{K}_{74} \mathrm{KKKIKR}_{80}\right)$ at the beginning of the aC-helix is a distinctive feature of CK2a (Tuazon \& Traugh, 1991; Guerra et al., 1999). Results from mutational studies support the notion that this cluster is involved in substrate recognition, inhibition by heparin, down-regulation by the CK2 $\beta$ subunit and interaction with heat shock protein 90, and nuclear targeting (Guerra et al., 1999; Pinna \& Meggio, 1997) (Table 1). CK2a mutants from Caenorhabditis elegans and Xenopus laevis (K74E/K75E and K75E/K76E, respectively) had lysines replaced by glutamic acid residues, which greatly affected the charge of this region in both mutant enzymes. The changes produced neither a significant increase in the $K_{m}$ of the CK2 $\alpha$ subunit for the casein and model peptide substrates nor changes in the affinity of the mutated CK2a subunit for the CK2 $\beta$ subunit during assembling a fully competent CK2 holoenzyme. The same mutations, however, had a significant effect on the affinity of CK2 $a$ for heparin and for other polyanionic inhibitors (Hu \& Rubin, 1990; Gatica at al., 1994). Complete suppression of heparin inhibition was observed with the quadruple mutated K74-77A CK2a used by Vaglio and collaborators (1996). These authors showed (1) that all the four basic residues at positions $74,75,76$, and 77 are implicated in heparin binding and (2) that the mutation of all of them was necessary to minimize heparin inhibition. Further mutagenesis studies showed that the additional basic residues cooperated with high heparin binding (apart from the 7477 quartet). These were mainly Arg191, Arg195 and Lys198 located in the p+1 loop. However, the triple mutant for the three non-Lys-rich segment residues was less effective in heparin inhibition than was the mutant resulting from quadruple mutation of the 74-77 cluster (Vaglio et al., 1996). The triple mutant in which Lys79, Arg80 and Arg83 were changed into alanines did not alter the $\mathrm{IC}_{50}$ (concentration needed to give $50 \%$ inhibition) value for heparin. However, the mutant did show a reduction in the phosphorylation efficiency of the peptide substrate (and derivatives in which individual aspartyl residues were replaced by alanines). Because of these properties, it was specified that the basic residues in positions 77-83 are mainly involved in substrate recognition, rather than in heparin inhibition (Sarno et al., 1995; Vaglio et al., 1996). These authors concluded that the highly conserved 74-80 basic stretch is composed of two functionally distinct entities: (1) an N-terminal moiety mostly involved in heparin inhibition as well as in down-regulation by the $\beta$ subunit and (2) the $C$-terminal part implicated in recognition of the crucial specificity determinant at positions $n+3$, but irrelevant to heparin. 
Extended mutagenesis analysis combined with biochemical characterization provided clear evidence that residues responsible for both substrate recognition and down-regulation of CK2 $\alpha$ catalytic activity are located mainly in the Lys-rich loop and p+1 loop spanning sequences 74-83 and 191-198, respectively. This corroborates the concept that the CK2 $\beta$ subunit down-regulates the CK2 $\beta$ by acting as a pseudosubstrate (Meggio et al., 1994; Sarno et al., 1996, 1997a, 1999).

Sarno and collaborators (1997b) analyzed the relative contribution of basic residues, presumably implicated in CK2-substrate interaction, in the recognition of peptide substrates varying in the number and position of acidic determinants. Sixteen derivatives of the optimal peptide substrate RRRA-DDSDDDDD, wild-type CK2 and twelve CK2a mutants defective in substrate recognition were used in the experiments. In the CK2 $\alpha$ mutants, different basic residues implicated in substrate recognition were replaced by alanine (e.g., K49A, K74-77A, or K79A/R80A/K83A). The results obtained support the idea that the acidic residues at positions $\mathrm{n}+1$ and $\mathrm{n}+3$ are essential, while additional acidic residues are required for efficient phosphorylation of CK2 substrates. Kinetic analysis with CK2 $\alpha$ mutants revealed that Lys48 was implicated in the recognition of the determinant at position $n+2$. Lys77 interacts with the determinants at $n+3$ and $n+4$, while Lys198 recognized the determinant at $n+1$ (Sarno et al., 1997b). Molecular modeling based on crystallographic data supported these observations. It showed that several of these basic residues are clustered around the active site, where they make contact with individual acidic residues of the peptide substrate, polyanionic inhibitors, regulatory elements present in the $\beta$ subunit, $N$-terminal segment of the CK2 $a$, and possibly other proteins interacting with CK2 (Sarno et al., 1999).

\subsubsection{Mutations of CK2 $\alpha$ in catalytic subdomains}

Subdomains II and VII of CK2a involved in nucleotide binding and phosphotransfer are in close proximity to each other in the three-dimensional structure. CK2a differs from more than $95 \%$ of other known protein kinases in having Val66 instead of the corresponding alanine within conserved region II and Trp176 instead of the corresponding phenylalanine within region VII (Allende \& Allende, 1995). To investigate whether these variant amino acid residues might be responsible for effective GTP utilization, Jakobi and Traugh (1995) mutated both of these residues back to the consensus amino acids. Their results indicated that both single mutants of CK2 $a$ and the double mutant CK2 $a$ could still use GTP as a phosphate donor. The single and double mutations only altered the relative affinities for ATP and GTP. This finding indicated that at least one other amino acid residue must be responsible for the effective utilization of GTP by CK2. The same authors studied the abovementioned mutants with respect to the catalytic activity of the reconstructed holoenzyme. The relatively lower affinity for GTP of the holenzyme reconstructed from the mutated CK2 $\alpha$ was caused by changes in both the $K_{m}$ and $V_{\max }$ values for GTP and ATP, while for the catalytic subunits, it was a result of changes in the $K_{m}$ values only. These studies showed that the unique property of the effective utilization of GTP by CK2 was correlated with stimulation of the activity by the regulatory subunits and with the ability to undergo a conformational change upon formation of the holoenzyme.

Srinivasan and collaborators (1999) showed that the dual specificity of CK2 probably originated from the loop situated around the stretch $\mathrm{H}_{115} \mathrm{VNNTD}_{120}$ in CKa. In their work, they combined site-directed mutagenesis of CK2 $a$ with comparative 3D-structure modeling. 
Due to significant amino acid sequence similarity (69,5\%), kinase CDK2 was chosen to be a good comparative model for CK2a. Based on modeling, a $\Delta$ N118 CK2a mutant was constructed. The kinase assay showed decreased affinity of this protein to GTP, in comparison to the wild-type CK2a. The $K_{m}$ values were 146 and $37 \mu \mathrm{M}$, respectively. The results obtained clearly indicate that the adenine/guanine binding region (His115-Asp120) is responsible for the dual specificity of kinase towards phosphate donors (Srinivasan et al., 1999).

The latter study was extended by Jakob and collaborators (2000), who created several mutants of Xenopus laevis CK2a with substitutions at positions 118 and 129. They tested them for cosubstrate specificity after their combination with CK2 $\beta$. The region containing Asn118, known to participate in the recognition of the guanine base, is a part of the sequence $\mathrm{N}_{117} \mathrm{NTD}_{120}$. This sequence closely resembles the conserved sequence NKXD that is present in G proteins and other GTPases. The study demonstrated that both the CK2 $a$ $\triangle \mathrm{N} 118$ and CK2a N118E mutants produced a 5 to 6 -fold increase in the $K_{m}$ for GTP with little effect on the affinity for ATP.

The mutagenesis by Yde and collaborators (2005) resulted in the first stable and fully active mutant of the human catalytic subunit of protein kinase CK2 that is devoid of dual cosubstrate specificity. The resulting mutant hsCK2a1-335 (human CK2 deleted for the last 56 amino acids) V66A/M163L was designed on the basis of several structures of the enzyme from Zea mays in a complex with various ATP-competitive ligands. As structural research revealed the existence of a purine base-binding plane harboring the purine base of ATP and GTP. This plane is flanked in human CK2a by two side-chains of Val66 and Met163, and it adopts a significantly different orientation than it does in other kinase homologues. By exchanging these two flanking amino acids, the cosubstrate specificity is shifted towards strongly favoring ATP. These findings demonstrated that CK2 $\alpha$ possesses a sophisticated structural adaptation that favors dual-cosubstrate specificity, a property that may have biological significance.

The mutagenesis studies also provided much insight into the significance of the sequence of the catalytic domain with respect to the CK2a/CK2 $\beta$ interaction. It was reported that $C K 2 \alpha$ V66A and V66A/W176F were able to interact with CK2 $\beta$, but this interaction failed to stimulate catalytic activity on the peptide substrate. These results were in contrast to the result with the wild-type a subunit, which was stimulated 4-fold. Nevertheless, the stimulatory response to the cationic modulatory compounds, spermine and polylysine, was the same for holoenzymes reconstituted with the wild-type subunit and all three abovementioned mutants of the a subunit. The results showed that there must be at least two different interactions between the catalytic $\alpha$ and regulatory $\beta$ subunit: one that is responsible for stimulation by the $\beta$ subunit itself and another for mediating the stimulation by polycationic compounds (Jakobi \& Traugh, 1992). However, experiments using calmodulin as a substrate for phosphorylation revealed that the insensitivity of the CK2 $a$ mutant V66A to CK2 $\beta$ was only apparent. Down-regulation of calmodulin phosphorylation by the CK2 $\beta$ subunit is even enhanced by the V66A mutant. This observation indicated a possible indirect role for Val66 in conferring to the a-subunit a conformation less sensitive to down-regulation (Sarno et al. 1997a).

It is known that the hydrophobic and polar residues of domain II and VII are responsible for the selectivity of a number of specific, potent CK2 ATP-competitive inhibitors, like TBBz 
(tetrabromobenzimidazole) and TBBt (tetrabromobenzotriazole) (Sarno et al., 2005a). The importance of the same key residues in the hydrophobic portion of the binding site was corroborated by mutational analysis of residues of the human CK2a. Their side chains contribute to the reduction in the internal size of the hydrophobic pocket adjacent to the ATP/GTP-binding site in CK2 (Battistutta et al., 2001; Sarno et al, 2005). Three of these residues (Val66 or Ile66, Ile174, and Met163) are specific to CK2. They are generally replaced by smaller ones in other protein kinases. Both single and double mutants with substitutions for Val66 and Ile174 gave rise to catalytically active CK2 $\alpha$ with altered susceptibility to various inhibitors. However, replacement of Met163 by glycine produced a catalytically inactive mutant (Sarno et al., 2005b). Similar data were obtained with yeast CK2a. Mutants with alterations to V67 and I213 (analogous to V66 and I174 of human CK2a) displayed considerably higher $K_{i}$ values toward inhibitors TBBz and TBBt and only a slight change in the affinity for ATP (Sajnaga et al, 2008). The structural basis for decreased emodin binding to human CK2a resulting from a single point mutation (V66A) has been examined by molecular dynamics (MD) simulations and energy analysis (Zhang \& Zhong, 2010). It was found that the V66A mutation resulted in a packing defect due to a change in hydrophobicity. It led to abnormal behavior of the glycine-rich loop, a-helix, and C-loop. The critical role of Ile66 in cosubstrate binding and selection, besides forcing the nucleotide ligands to adopt different positions in the binding pocket, was also demonstrated in a mutational study (Jakobi et al., 1994; Jakobi \& Traugh, 1992, 1995).

Chaillot and collaborators (2000) studied the role of Gly177 in conserved region VII of the catalytic domain, which is close to the active site. It was revealed that the CK2a G177K mutant exhibited improved catalytic efficiency for acid peptidic substrates, probably by establishing interactions with the acidic residues.

The acidic residue Asp or Glu of the catalytic loop (corresponding to Glu170 in PKA and conserved in most Ser/Thr protein kinases) is responsible for the binding of basic residues that specify the protein/peptide substrates. In CK2, the residue is replaced by a histidine (His160). Such a substitution could explain the acidophilic properties of CK2, in contrast to the basophilic properties of PKA and other Ser/Thr kinases. The actual role of the His160 in the determination of the site specificity of CK2 was assessed by Dobrowolska and collaborators (1994). Interestingly, subsequent mutational studies in which His160 was replaced with alanine or aspartic acid ruled out any significant role of this residue in substrate recognition (Sarno et al., 1997b).

A CK2 $\alpha$ inactive mutant (D156A) was produced based on structural homology to kinase PKA. The mutant protein was able to compete efficiently with the wild-type CK2 $\alpha$ for the regulatory $\beta$ subunits. Although it does not exhibit kinase activity, the D156A mutant can bind CK2 $\beta$ to form an inactive holoenzyme. Moreover, the mutant abolishes the inhibitory effect of CK2 $\beta$ on CK2 $\alpha$-mediated phosphorylation of calmodulin. These results suggest that CK2 $\alpha$ D156A may be a useful dominant-negative mutant for elucidation of the cellular functions of the CK2 regulatory subunit (Cosmelli et al., 1997).

\subsubsection{Mutations of CK2 $\alpha$ in the glycine-rich loop}

The glycine-rich sequence (G-loop) is one of the most critical structures of protein kinases, since it contributes in many ways to enzyme activity. This multifunctional structural 
element participates in nucleotide binding, substrate recognition, catalysis, and regulation of activity (Bossemeyer et al., 1994). In their extensive mutational studies combined with biochemical characterization, Sarno and collaborators (1999) confirmed that some basic residues in the glycine-rich loop of the CK2a, particularly Lys49, are implicated in substrate recognition and inhibition by polyanions. Another residue located within this region, Gly48, is involved in binding the ATP phosphate moiety. Replacement of Gly 48 by alanine in CK2 $\alpha$ affected its catalytic efficiency and specificity. It is thought that alanine causes this phenotype by creating an electrostatic barrier between ATP and the peptide substrate (Chaillot et al., 2000).

\subsubsection{Mutations of CK2 $\alpha$ in the C-terminal region}

The C-terminal region of vertebrate CK2 $\alpha$ is composed of 54 amino acids. Knowledge of this segment is rather poor, except for phosphorylation by kinase p34Cdc2 and interaction with isomerase Pin1 (Bosc et al., 1995; Messenger et al., 2002). It is known from the publications on crystallization of CK2 that the catalytic subunits are particularly sensitive to degradation, which makes the crystallization process of the entire subunit difficult (Niefind et al., 2000, 2001). Truncation at the C-terminus reduced the intrinsic degradability of CK2 $\alpha$ and allowed its crystallization and the determination of its 3D structure. Starting from sequence alignments of C-termini from different CK2 $\alpha$ s, Grasselli and collaborators (2004) constructed a mutant carrying the substitution of two distal prolines with alanines (P382A/P384A). Most intriguing was the resistance of the mutant to proteolytic degradation, which makes this protein an excellent candidate for crystallization of the entire CK2 $\alpha$ subunit.

Bischoff and collaborators (2011) have recently determined for the first time the structure of the full-length human $\mathrm{CK} 2 \alpha^{`}{ }^{\mathrm{C} 336 \mathrm{~S}}$ subunit. A point mutation of $\mathrm{CK} 2 \alpha^{\prime}$ was necessary to prevent covalent dimerization from intermolecular disulfide bridges formed by Cys336. However, these results shed light on the differences between the two catalytic subunits, $\alpha$ and $\alpha^{`}$ (e.g., significantly lower affinity of $\mathrm{CKa}^{`}$ towards $\mathrm{CK} 2 \beta$ relative to that of $\mathrm{CK} 2 \alpha$ ).

\subsubsection{Mutagenesis of CK2 $\alpha$ in other regions}

Determination of the structure of the CK2 holoenzyme and individual subunits provided knowledge about the nature and location of the interface between catalytic and regulatory subunits (Niefind et al., 2001). Using structure-guided alanine-scanning mutagenesis combined with isothermal titration calorimetry (ITC), energetic "hot spots" were identified on the surface of CK2 $\alpha$ that determine the $\alpha / \beta$ subunit interaction (Raaf et al., 2011). Three single and one double $\mathrm{CK} 2 \alpha$ subunit mutants were produced, in which individual hydrophobic amino acids located within the CK2 $\alpha$ interface were replaced by alanine. The ITC analysis of CK2 $\alpha$ mutants revealed that substitution of Leu41 and Phe54 were most disruptive to binding of CK2 $\beta$. Moreover, the L41A and F54A mutants retained their kinase activity, compared to the wild-type CK2. Based on the results mentioned above, it can be claimed that these residues are suspected of being interaction "hot spots" (Raaf et al., 2011).

The amino-acid sequence and the structure of yeast protein kinase CK2 $\alpha$ differ from those of CK2 $\alpha^{\prime}$ and other eukaryotic CK2a subunits. CK2a is unique in containing a 38-amino-acid loop consisting of two a-helical structures situated close to structures engaged in ATP/GTP 
and substrate binding (Niefind et al., 2001). Modeling of the tertiary structure of the CK2a showed that, after removing both a-helical motifs, the CK2 $\alpha$ subunit assumes a structure that is more similar to that of CK2 $\alpha^{\prime}$ than it is to the structure of intact CK2a. The deletion of the 38 amino acids from CK2a drastically decreases its catalytic efficiency. Its characteristics are similar to yeast $\mathrm{CK} 2 \alpha^{\prime}$ with respect to sensitivity to salt, heparin and spermine (Sajnaga et al., 2008) (Fig. 3).
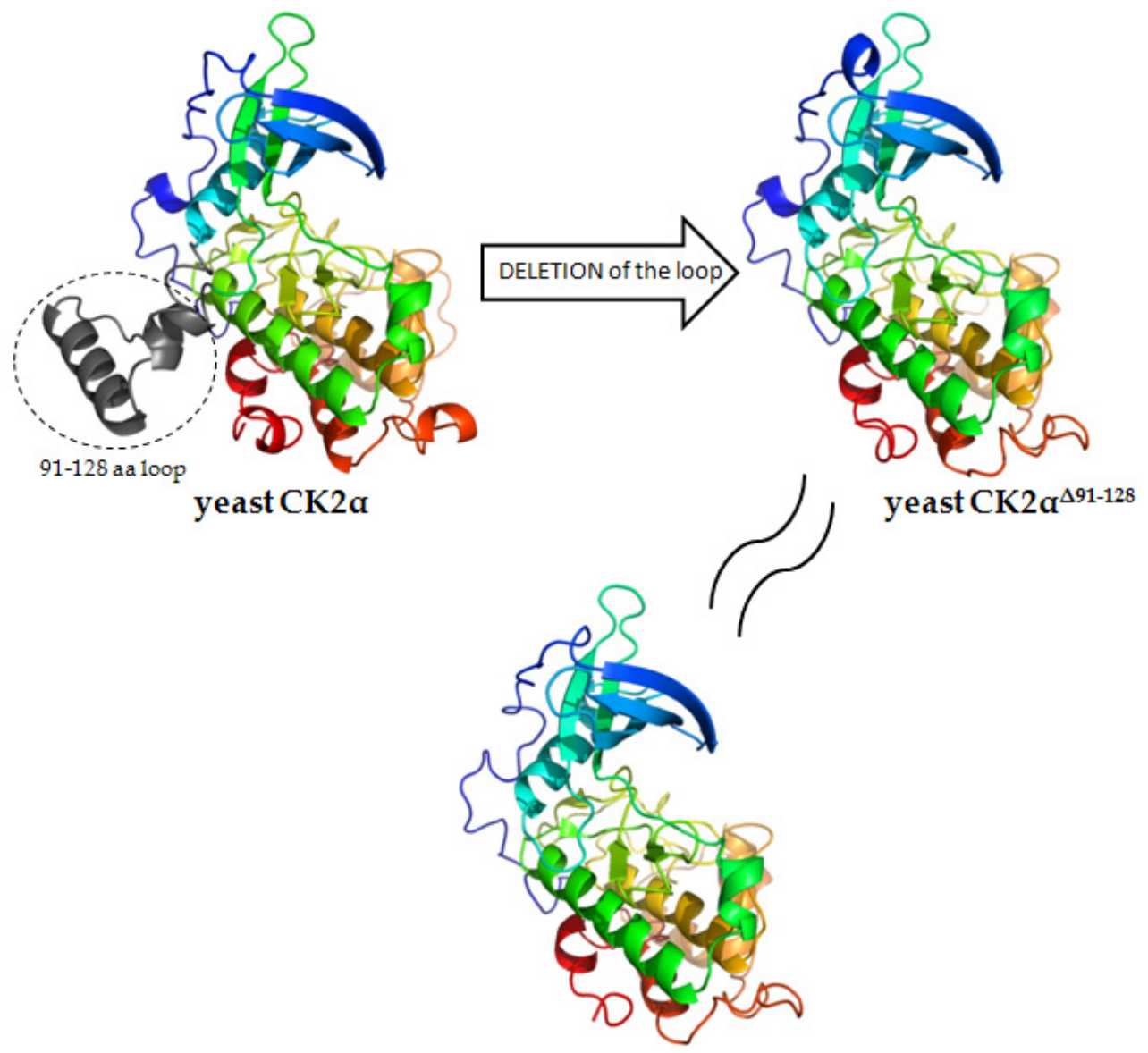

yeast CK2 a`

Fig. 3. Conformational consequences of mutagenesis of the yeast CK2 $\alpha$ catalytic subunit. 


\begin{tabular}{|c|c|c|c|}
\hline CK2 residues & Location & Mutant & Reference/source \\
\hline \multicolumn{4}{|c|}{ Substrate recognition and inhibition by polyanions } \\
\hline K49 & Subd. I; Gly loop & K49A & Sarno et al., 1999 \\
\hline \multicolumn{4}{|l|}{ K74 } \\
\hline \multirow[t]{2}{*}{ K75 } & Subd. II/III, Lys rich loop & \multirow[b]{2}{*}{ K74-77A, K77A } & Sarno et al., 1997a, 1998, \\
\hline & & & 1999, Vaglio et al. 1996 \\
\hline \multicolumn{3}{|l|}{ K76 } & Gatica et al., $1994^{1}$ \\
\hline \multicolumn{4}{|l|}{ K77 } \\
\hline \multicolumn{4}{|l|}{ K79 } \\
\hline R80 & Subd. III, Helix C & $\begin{array}{l}\text { K79A, } \\
\text { R80A/K83A }\end{array}$ & Sarno et al., 1998, 1999 \\
\hline \multicolumn{4}{|l|}{ K83 } \\
\hline K122 & Subd.V, Linker region & K122A & Sarno et al., 1997a, 1999 \\
\hline H160 & Subd. VIb, Catalytic loop & H160D & Dobrowolska et al., 1994 \\
\hline \multicolumn{4}{|l|}{ R191 } \\
\hline R195 & Subd. VIII, p+1 loop & R191, 195, K190A & Sarno et al., 1997a, 1998, \\
\hline K190 & & K198A & 1999; Vaglio et al., 1996 \\
\hline \multicolumn{4}{|l|}{ K198 } \\
\hline \multicolumn{4}{|c|}{ Catalytic efficiency and specificity } \\
\hline G482 & Subd. I, Gly loop & G48D & Chaillot et al., 2000 \\
\hline V66 & Subd. II & V66A & \\
\hline M163 & Subd. VIb & $C K 2 a^{1-335}$ & Yde et al., 2005 \\
\hline
\end{tabular}




\begin{tabular}{|c|c|c|c|}
\hline V66 & Subd. II & & \\
\hline & & V66A/I174A & Sarno et al., 2005 \\
\hline I174 & Subd. VII & & \\
\hline V66/W176 & Subd. II, Subd. VII & V66A/W176F & $\begin{array}{l}\text { Jakobi and Traugh, 1992, } \\
1995\end{array}$ \\
\hline N118 & $\begin{array}{l}\text { Subd. V, ATP/GTP binding } \\
\text { region }\end{array}$ & $\begin{array}{l}\text { N118A, } \\
\text { CK2 } a^{\Delta N 118}\end{array}$ & $\begin{array}{l}\text { Srinivasan et al., 1999; } \\
\text { Jakob et al., } 2000\end{array}$ \\
\hline D156 & Subd. VIb & D156A & Cosmelli et al., 1997 \\
\hline M163 & Subd. VIb & M163G & Sarno et al., 2005 \\
\hline G177 & Subd. VII & G117K & Chaillot et al., 2000 \\
\hline N189 & Subd. VII, Activating segment & N189R & Srinivasan et al., 1999 \\
\hline \multicolumn{4}{|c|}{ Regulation by $\beta$ subunit } \\
\hline L41 & Subd. I & L41A & Raaf et al., 2011 \\
\hline L54 & Subd. I, ATP/GTP binding region & L54A & Raaf et al., 2011 \\
\hline V66 & Subd. II & V66A, & Sarno et al., 1997b \\
\hline W176 & Subd. VII & V66A/W176F & Jakobi \&Traugh, 1992 \\
\hline \multicolumn{4}{|c|}{ Constitutive activity } \\
\hline M6 -V30 & $\mathrm{N}$-terminus & $\Delta 2-12, \quad \Delta 2-18$ & Sarno et al., 2001, 2002; \\
\hline Y125 & Subd. V, Hinge region & $\mathrm{Y} 125 \mathrm{~F}^{4}$ & Cristiani et al., 2011 \\
\hline E180 & Subd. VII, Activation segment & E180A & Sarno et al., 2002 \\
\hline
\end{tabular}




\begin{tabular}{llll}
\hline E182 & Subd. VII, Activation segment & Y182F & Sarno et al., 2002 \\
\hline Stability & & & \\
\hline M336-Q393 & C-terminus & E336-393 & Ermakova et al., 2003 \\
\hline P382 & C-terminus & P382A & Grasselini et al., 2004 \\
P384 & P384A & Bischoff et al., 2011 \\
\hline C336 3 & C-terminus & C336S & \\
\hline
\end{tabular}

aThe residue numbers correspond with those of human CK2a, unless otherwise indicated. The Roman numerals indicate the eleven conserved subdomains present in the catalytic domain of all protein kinases (Hanks \& Hunter, 1995). Abbreviations: ${ }^{1} \mathrm{CK} 2 \alpha$ from Xenopus laevis; ${ }^{2} \mathrm{CK} 2 \alpha$ from Yarrovia lipolytica; ${ }^{3}$ Human CK2 $\alpha^{\prime}$; ${ }^{\text {in }}$ silico mutation.

\section{Table 1. Summary of CK2a mutantsa}

The deletion of the loop of amino acids 91-128 from yeast CK2a led to behavioral and structural similarity to CK2 $\alpha^{\prime}$ (Sajnaga et al., 2008). The 3D models of proteins were created using the SWISS-MODEL software based on protein structure templates (PDB code 1ds5D) available in the Protein Data Bank and visualized with the PyMOL software.

Chimeras of different kinases can be easily engineered using recombinant DNA technology and used in studies on the structure and function of kinase. To study the effect of CK2 $\beta$ on the activity of CK1a, Jedlicki and collaborators (2008) generated CK2a/CK1a chimeras that were able to bind tightly to the CK2 $\beta$ regulatory subunit, but maintain the peptide substrate specificity of CK1. This is related to the capacity of the CK2 $\beta$ to regulate the activity of $\mathrm{CK} 2 \alpha$, as well as other protein kinases, such as A-Raf, C-Mos, and Chk1. It has been shown that a chimera combining a large part of the CK1a kinase with the $\mathrm{N}$-terminal region of CK2 $\alpha$ that is responsible for binding CK2 $\beta$ can be stimulated by this subunit. It is possible that such chimeras could be used to test the presence of "the docking site" on the CK2 $\beta$ subunit, which would bring substrate molecules near the catalytic subunits.

\subsection{Mutagenesis of the regulatory subunit CK2 $\beta$}

From the primary sequence of the $\beta$ subunit, it is obvious that the charged amino acids are not equally distributed. The acidic residues are clustered in the N-terminal half, whereas the basic residues are clustered in the C-terminal part of the molecule. Mutational studies have shown that, in contrast to cyclins, which invariably act as indispensable activators of CK2related CDKs, the CK2 $\beta$ subunit fulfills antagonist functions. The features of CK2 $\beta$ can be explored by generating large synthetic fragments, some of which reproduce the C-terminal moiety and thus stimulate its catalytic activity. Fragments reproducing segments of the Nterminal sequence are inhibitory, which becomes especially evident when calmodulin is the substrate (Marin et al, 1992, 1995; Meggio et al, 1994; Sarno et al, 1997a). 


\subsubsection{Mutations of CK2 $\beta$ that affect autophosphorylation}

The CK2 $\beta$ subunit is known to be autophosphorylated by the catalytic subunit. Autophosphorylation occurs on serine residues at positions 2 and 3 in the amino-terminal region of the molecule. Both these serines fit CK2 consensus specificity requirements (Marin et al, 1992). This finding was corroborated by the fact that the mutant S2,3G (i.e., S2G/S3G) is completely incapable of autophosphorylation (Hinrichs et al, 1993). Deletion of the first four amino acids (CK2 $\beta \Delta 1-4)$, which eliminated autophosphorylation of CK2 $\beta$, had no significant effect on the reconstruction of CK2 holoenzymes nor on their catalytic activity, thermostability, and responsiveness to polylysine. Unlike the wild-type CK2 $\beta$, however, CK2 $\beta \Delta 1-4$ failed to confer to the reconstituted holoenzyme the typical responsiveness to $\mathrm{NaCl}$ stimulation. These results indicated that autophosphorylation sites are not required on CK2 for conferring a stable structure and full catalytic activity. In contrast an autophosphorylation site is implicated in the $\mathrm{NaCl}$-dependent fine-tuning of CK2 activity (Meggio et al., 1993). Interestingly, the acidic stretch heavily influences autophosphorylation of the $\beta$ subunit, even though Ser 2 is more than 50 amino acids away in the primary sequence (Boldyreff et al., 1994).

\subsubsection{Mutations of CK2 $\beta$ that affect binding with CK2 $\alpha$}

In order to shed light on the mechanisms by which the CK2 $\beta$ subunits affect the catalytic properties of CK2 and to elucidate the molecular interactions between the catalytic and regulatory subunits of CK2, Boldyreff and collaborators $(1992,1993)$ generated a number of mutants of the CK2 $\beta$ subunit, which were tested for their ability to functionally replace the wild-type CK2 $\beta$. These authors showed that deletion of the last 44 residues of the C-end (CK2 $\beta \Delta 171-215)$ eliminated the capacity to form tetramers with CK2 $\alpha$ and to stimulate activity. However, deletion of the last 34 amino acids (CK2 $\beta \Delta 181-215)$ yielded an active CK2 $\beta$ that had lower affinity for CK2 $\alpha$. Shorter deletions (e.g., CK2 $\beta \Delta 194-215)$ did not affect the interaction between the catalytic and regulatory subunits of CK2. Boldyreff and collaborators demonstrated that deletion mutants in which the last 45 or more amino acids are missing were not able to assemble with the a subunit. These data identified the Cterminal segment of CK2 $\beta$ as essential for association with the CK2 $\alpha$ subunit, with special reference to its 171-180 stretch, which is indispensable both to form tetrameric CK2 and to stimulate activity of the CK2 $\alpha$ catalytic subunit (Boldyreff et al., 1994). Tight interaction between the CK2 $\alpha$ and CK2 $\beta$ subunits, accomplished by the C-terminal part of the CK2 $\beta$ subunit, was also described (Kusk et al., 1995; Marin et al., 1997).

Mutagenesis along with crosslinking and peptide studies have shown that the acidic amino acid stretch of CK2 $\beta$ from residues 55-64 interacts with a corresponding basic stretch of the CK2a subunit. However, these weak electrostatic interactions seem to determine the activity of, but not the formation of, the CK2 holoenzyme (Krehan et al., 1996, Sarno et al, 1997b).

Kusk and collaborators (1995) used mutagenesis of CK2 subunits with a yeast two-hybrid system to explore domains involved in intersubunit contact. [In the yeast two-hybrid system, a peptide or protein is fused to part A of a transcriptional activator. Another peptide or protein is fused to part B. Transcriptional activation of an easily assayed reporter gene occurs only when part A and part B come together. Parts A and B 
themselves cannot interact to form the transcriptional activator, nor can either part individually (part $\mathrm{A}$, the part $\mathrm{A}$ fusions, part $\mathrm{B}$, and the part $\mathrm{B}$ fusions) cause the reporter to be expressed. However, if the fusions interact, part A and part B can come together, and the reporter is activated. This is an indication that the peptides or proteins in the fusions can interact.] A series of plasmid constructs was prepared. They encoded Nterminal or C-terminal truncations of the CK2 $\alpha$ and CK2 $\beta$ subunits to indicate which regions of the subunits were engaged in CK2 holoenzyme formation in yeast cells. The data revealed that the regulatory CK2 $\beta$ subunit has a modular structure. An N-terminal domain (residues 20-145) is responsible for homodimerization (CK2 $\beta / C K 2 \beta$ ). A Cterminal domain (residues 152-200) is necessary for heterodimerization (CK2 $\alpha / C K 2 \beta$ ). Amino acid residues 1 to 20 in the N-terminus and 351 to 391 in the C-terminus of CK2 $\alpha$ are dispensable for interaction with the regulatory subunit.

\subsubsection{Mutations of CK2 $\beta$ that affect the activity of CK2 $\alpha$}

The modulation of CK2a subunit activity by CK2 $\beta$ has a stimulatory effect on most substrates. However, when calmodulin is used as the substrate, the CK2 $\beta$ subunit almost completely inhibits the activity of the catalytic subunit (Guerra et al., 1999). This inhibition can be overcome by addition of polylysine (Meggio et al, 1992). Mutagenesis studies on the CK2 $\beta$ subunit revealed an acidic stretch (amino acids 55-64) that is responsible for the inhibitory effect and for the stimulation by polylysine (Meggio et al., 1994). Interestingly, mutants of CK2 $\beta$ bearing substitutions at positions 55, 57, and 59-64 to alanine produced up to 4 -fold more active holoenzyme after assembling with the catalytic a subunit than did the wild type. At the same time, these mutants were refractory to the stimulatory effect of polylysine. This finding revealed that the acidic N-terminal cluster of CK2 $\beta$, especially Asp55 and Glu57, is involved in intrinsic down-regulation of CK2 basal activity and has been implicated in responsiveness to various effectors (Boldyreff et al., 1993, 1994).

Other data provided by Hinrichs and collaborators (1995) demonstrated that Pro58 located in the center of the acidic segment also constitutes an important structural feature affecting the function of down-regulation of CK2 $\beta$ towards the catalytic subunits. The effect of a mutation of proline to alanine resulted in an effect that was similar to mutation of the acidic residues alone. It produced hyperactive $\mathrm{CK} 2 \beta$ subunits that stimulated the CK2 $\alpha$ activity to a greater extent than did the wild-type CK2 $\beta$ subunit.

\subsubsection{Mutations of CK2 $\beta$ that affect export of the holoenzyme}

It is known that protein kinase CK2 is present in not only the cytoplasm, nuclei, and several other cell organelles, but also on the external side of the cellular membrane (Kubler et al, 1983). Rodrigez and collaborators (2008) have studied the role of CK2 $\beta$ in the export of the holoenzyme to the extracellular membrane through deletion and point mutations. The region of CK2 $\beta$ between amino acids 20 and 33 was found to be necessary, but not sufficient, to allow the catalytic subunits to function as an ectokinase. An important function of this region is fulfilled by Phe21 and Phe22, which anchor the loop of the 20-33 sequence. Another key element of this region is constituted by the acidic residues in positions 26-28. They are exposed to the medium, free to interact with other proteins (Bolanos-Garcia et al, 2006). 


\subsubsection{Mutation of CK2 $\beta$ that affects its stability}

Overexpression of CK2 catalytic subunits leads to increased cell proliferation and transformation, while overexpression of the regulatory CK2 subunit is associated with decreased proliferation in yeast and mammalian cells (Li et al., 1999; Lebrin et al., 2001; Vilk et al., 2001). Moreover, CK2 $\beta$ is physiologically expressed at a higher level than CK2 $a$, and the excess of the regulatory subunit is rapidly ubiquitinated and degraded in a proteasomedependent manner (Luscher \& Litchfield, 1994; Zhang et al., 2002). To protect CK $\beta$ from the degradation machinery and to stabilize it, six surface-exposed lysine residues were mutated to arginine (French et al., 2007). The 6KR mutant functioned as normal CK2 $\beta$, but it was not sensitive to proteasome inhibition. The physiological role of mutagenesis-mediated CK2 $\beta$ stabilization was also examined with the use of cell proliferation assays. A significant decrease in proliferation was observed in cells expressing the $6 \mathrm{KR}$ mutant when compared to wild-type CK2 $\beta$. The authors suggest that the stabilized form of the CK2 regulatory subunits can be utilized to inhibit cell proliferation in cancer cells (French et al., 2007).

\subsection{Mutagenesis of CK2 substrates}

Protein kinase CK2 is a multi-substrate enzyme with a large number of cellular partners. In 2003, Meggio and Pinna updated the list of 307 CK2 substrates with 308 sites phosphorylated by CK2 (Meggio \& Pinna, 2003). This number is now out-of-date, as novel CK2 protein substrates are discovered every year. A bona fide CK2 substrate may possess one or several phosphoacceptor sites affected by CK2, but an analysis of the initial amino acid sequences of possible CK2 partners may show a dozen or so putative CK2 sites. Sitedirected mutagenesis is a useful tool to create CK2 substrate mutants. Such proteins are produced (1) to indicate precisely the phosphorylatable amino acid, (2) to study the physiological significance of CK2-mediated phosphorylation of a given protein substrate, or (3) to confirm the physiological relevance of CK2-mediated phosphorylation. Presented below are several examples of the mutagenesis of CK2 substrates.

Mdm2 is a cellular oncoprotein that down-regulates the growth suppressor protein p53 (Barak et al., 1992). Computer analysis of the amino acid sequence of Mdm2 revealed 19 putative CK2 phosphorylation sites. Three Mdm2 mutants with deletions at codons 1-114, 93-285, and 271-491 were produced to exclude sites that are not affected by CK2. The phoshorylation assays revealed that only the central part of Mdm2 is phosphorylated. Based on further detailed analysis of the remaining CK2 consensus sites, Ser269 was chosen to be the most promising. Using overlap extension PCR (see section 2.7 in the chapter by Sturtevant), the Mdm2 point mutant S269A was constructed and the relevant CK2 phosphorylation site was finally discovered (Götz et al., 1999).

In some protein substrates, putative CK2 phosphorylation sites are located close to one another, and thus several point mutants had to be produced to score them. The consensus sequence analysis of the N-terminal domain of the human transcription factor Tcf- 4 indicated multiple sites that fit the motif for CK2 phosphorylation. No CK2-mediated phosphorylation was detected on the Tcf-4 fragments comprising amino acids 1-30 and 1-49. Thus, the best candidates for CK2-affected amino acids were the serine residues located in the Tcf-4 peptide $\mathrm{T}_{54} \mathrm{NQDSSSDSEAERRP}_{68}$. Three Tcf- 4 mutants, one triple point mutant (S58A/S59A/S60A) and two single point mutants (S58E and S60E) were made to help indicate the phosphorylatable amino acid. In vitro phosphorylation assays revealed that all three adjacent serines are modified by CK2 with different efficiencies (Miravet et al., 2002). 
Sic1 is a yeast protein that specifically inhibits $\mathrm{Clb} / \mathrm{Cdk}$ activity in the $\mathrm{G} 1$ phase, so that DNA replication is suppressed (Verma et al., 2001; Nash et al., 2001). Moreover, Sic1 undergoes multistep phosphorylation. Therefore, Sic1 phosphorylation occurs at several positions. One looks like the CK2 consensus site. CK2-mediated phosphorylation of Sic1 within the $\mathrm{Q}_{199}$ ESEDEED sequence was confirmed both in vitro and in vivo in Saccharomyces cerevisiae cells (Coccetti et al., 2004, 2006). Mutations of the CK2 consensus site on Sic1 (S201A and S201E) alter the coordination between cell growth and division. They also change the level and time-course of S-Cdk kinase activity. These mutation data strongly support the physiological relevance of Sic1 phosphorylation for inhibitory activity (Coccetti et al., 2004).

The regulatory effect of CK2 activity on the Wnt signaling pathway is widely known (Pinna, 2002; Litchfield, 2003). Kinase phosphorylates and interacts with $\beta$-catenin and thus enhances the stability and transcriptional activity of $\beta$-catenin (Song et al, 2003; Seldin et al, 2005). The AKT/PKB kinase is also a well-known CK2 substrate and interacting partner. CK2-mediated phosphorylation at Ser129 causes AKT hyperactivation (Di Maira et al, 2005; Guerra, 2006). CK2 may link the two pathways..

To elucidate the roles of CK2 in the Wnt and AKT/PKB signaling pathways, the AKT phosphorylation-deficient mutant (S129A) was overexpressed in an embryonic cell line. The $\beta$-catenin-dependent transcriptional activity was analyzed. The data obtained indicate that blockage of AKT phosphorylation by CK2 impairs $\beta$-catenin activity and decreases its stability. Therefore, CK2-mediated AKT phosphorylation at Ser129 is a necessary step in the up-regulation of the $\beta$-catenin transcriptional activity in human embryonic kidney cells (Ponce et al., 2011).

Besides phosphorylation of numerous cellular proteins, CK2 directly interacts with many of them forming protein-protein complexes (Litchfield, 2003). Both catalytic and regulatory CK2 subunits can interact with different proteins, independently of the holoenzyme (Bibby et al., 2005). Wee1 kinase, involved in cell cycle progression, is one such CK2 protein partner. The Wee1 kinase is a key inhibitor of cyclin-dependent kinase (CDK1) and mitotic entry in eukaryotes. Several deletion mutants of the Wee1 catalytic domain were produced to investigate the interaction with CK2 subunits. Immunoprecipitation experiments revealed that Wee1 binds CK2 $\beta$ via two domains of Wee1 (comprising amino acids 59-71 and 232332) and two regions of CK2 $\beta$ (comprising residues 1-5 and 155-170). Although the interaction does not affect Wee1 activity, it up-regulates CDK1 by reversing the Wee1mediated inhibitory effect on CDK1. These findings reinforce the notion that CK2 $\beta$ can serve other protein kinases. It may be a universal regulatory subunit that can act independently of the CK2 holoenzyme (Olsen et al., 2010).

\section{Conclusion}

Even 58 years after its first description (Burnett \& Kennedy, 1954), the story of protein kinase CK2 has not been fully clarified. This enzyme catalyzes phosphorylation of over 300 substrates. They are characterized by having multiple acidic residues surrounding the phospho-acceptor amino acid. Consequently, CK2 plays a key role in several physiological and pathological processes (Guerra \& Issinger, 2008). After all those years of research, we are still asking the question: how is it possible that one kinase can be involved in so many 
different biochemical processes in the cell? Using different biochemical and genetic methods, we have solved several problems connected with the structure and mechanism of the catalytic action of this enigmatic protein kinase. The application of mutagenesis methods in many cases has helped us and will continue to help us get answers to many problems connected with CK2 activity. Among them are the following:

- $\quad$ The interaction between subunits

- $\quad$ Catalytic specificity and efficiency

- Substrate recognition

- $\quad$ Regulation by the $\beta$-subunit

- Stability of the subunits

- Interactions with modulators and substrates

- The effect of phosphorylation on catalytic activity

- Constitutive CK2 activity.

A protein kinase, such as CK2, is difficult to explore with respect to its physiological functions. CK2 has been shown to be involved in numerous aspects of cell proliferation and survival, including cell cycle progression and apoptosis control (Ahmad et al., 2008; Ahmed et al., 2002; Batistuta, 2009; Gyenis \& Litchfield, 2008; Meggio \& Pinna, 2003; Litchfield, 2003). Alterations in the levels or activity of CK2 have been implicated in a variety of human diseases, including cancers (Guerra \& Issinger, 2008). All these observations raise important questions regarding the mechanisms that control CK2 activity and specificity. These questions have a special value, since defects in regulation of these processes could contribute to tumorigenesis.

In this context, the application of mutagenesis methods, together with other techniques (e.g., molecular modeling), may be very useful in designing highly effective and specific inhibitors that are promising for CK2-based target therapy.

\section{Acknowledgement}

The 3D protein structure models of CK2 were kindly constructed by Maciej Masłyk, PhD. (Department of Molecular Biology, Institute of Biotechnology, The John Paul II Catholic University of Lublin, Poland)

\section{References}

Ahmad K.A., Wang G., Unger G., Slaton J., Ahmed K. (2008) Protein kinase CK2 - A key suppressor of apoptosis. Advances in Enzyme Regulation, Vol. 48, No. 1, (April 2008), pp. 179-187, ISSN 0065-2571.

Ahmed, K., Gerber, D.A., Cochet, C. (2002) Joining the cell survival squad: an emerging role for protein kinase CK2. Trends in Cellular Biology, Vol. 12, No. 5, (May 2002), pp. 226-230, ISSN 0962-8924.

Adler, V., Pincus, M.R., Minamoto, T., Fuchs, S. Y., Bluth, M.J., Brandt-Rauf, P.W., Friedman, F.K., Robinson, R.C., Chen, J.M., Wang, X.W., Harris, C.C. \& Ronai, Z. (1997). Conformation-dependent phosphorylation of p53. Proceedings of the National Academy of Sciences of the United States of America, Vol. 94, No. 5, (March 1997), pp. 1686-1691, ISSN 0027-8424. 
Allende, J. E. \& Allende, C.C. (1995). Protein kinases. 4. Protein kinase CK2: an enzyme with multiple substrates and a puzzling regulation. The FASEB Journal, Vol. 9, No. 5, (March 1995), pp. 313-323, ISSN 0892-6638.

Arnold K., Bordoli L., Kopp J., Schwede T. (2006) The SWISS-MODEL workspace: a webbased environment for protein structure homology modelling. Bioinformatics Vol.22, No. 2, (January 2006), pp. 195-201, ISSN 1367-4803

Barak, Y. \& Oren, M. (1992). Enhanced binding of a $95 \mathrm{kDa}$ protein to p53 in cells undergoing p53-mediated growth arrest. The EMBO Journal, Vol. 11, No. 6, (June 1992), pp. 2115-2121, ISSN 0261-4189.

Battistutta, R. (2009) Protein kinase CK2 in health and disease: Structural bases of protein kinase CK2 inhibition. Cellular and Molecular Life Sciences, Vol. 66, No. 11-12, (June 2009), pp. 1868-1889, ISSN 1420-682X.

Battistutta, R., Sarno, S., De Moliner, E., Marin, O., Issinger, O.-G., Zanotti, G., Pinna, L.A. (2000)_The crystal structure of the complex of Zea mays alpha subunit with a fragment of human beta subunit provides the clue to the architecture of protein kinase CK2 holoenzyme. European Journal of Biochemistry 267, No. 16, (August 2000), pp. 5184-5190, ISSN 0014-2956.

Battistutta, R., De Moliner, E., Sarno, S., Zanotti, G. \& Pinna, L.A. (2001). Structural features underlying selective inhibition of protein kinase CK2 by ATP site-directed tetrabromo-2-benzotriazole. Protein Science, Vol. 10, No. 11, (November 2001), pp. 2200-2206, ISSN 0961-8368

Bibby, A.C. \& Litchfield, D.W. (2005). The multiple personalities of the regulatory subunit of protein kinase CK2: CK2 dependent and CK2 independent roles reveal a secret identity for CK2beta. International Journal of Biological Sciences, Vol. 1, No. 2, (April 2005), pp. 67-79, ISSN 1449-2288

Bischoff, N., Olsen, B., Raaf, J., Bretner, M., Issinger, O.-G. \& Niefind, K. (2011). Structure of the human protein kinase CK2 catalytic subunit CK2alpha' and interaction thermodynamics with the regulatory subunit CK2beta. Journal of Molecular Biology, Vol. 407, No. 1, (March 2011), pp. 1-12, ISSN 1089-8638.

Becker, W., Weber, Y., Wetzel, K., Eirmbter, K., Tejedor, F.J., Joost, H.-G. (1998) Sequence characteristics, subcellular localization, and substrate specificity of DYRK-related kinases, a novel family of dual specificity protein kinases. The Journal of Biological Chemistry, Vol. 273, No. 40, (October 1998), pp. 25893-25902, ISSN 0021-9258.

Biondi R.M. and Nebreda A.R. (2003) Signalling specificity of Ser/Thr protein kinases through docking-site-mediated interactions. Biochemical Journal, Vol. 372, Pt. 1, (May 2003), pp. 1-13, ISSN 0264-6021.

Bolanos-Garcia, V.M., Fernandez-Recio, J., Allende, J.E. \& Blundell, T.L. (2006). Identifying interaction motifs in CK2beta--a ubiquitous kinase regulatory subunit. Trends in Biochemical Sciences, Vol. 31, No. 12, (December 2006), pp. 654-661, ISSN 0968-0004.

Boldyreff, B., Meggio, F., Pinna, L.A. \& Issinger, O.-G. (1992). Casein kinase-2 structurefunction relationship: creation of a set of mutants of the beta subunit that variably surrogate the wildtype beta subunit function. Biochemical and Biophysical Research Communications, Vol. 188, No. 1, (October 1992), pp. 228-234, ISSN 0006-291X 
Boldyreff, B., Meggio, F., Pinna, L.A. \& Issinger, O.-G. (1993). Reconstitution of normal and hyperactivated forms of casein kinase-2 by variably mutated beta-subunits. Biochemistry, Vol. 32, No. 47, (November 1993), pp. 12672-12677, ISSN 0006-2960

Boldyreff, B., Meggio, F., Pinna, L.A. \& Issinger, O.-G. (1994). Protein kinase CK2 structurefunction relationship: effects of the beta subunit on reconstitution and activity. Cellular \& Molecular Biology Research, Vol. 40, No. 5-6, (January 1994), pp. 391-399, ISSN 0968-8773

Boldyreff, B., James, P., Staudenmann, W., Issinger, O.-G. (1993) Ser2 is the autophosphorylation site in the beta subunit from bicistronically expressed human casein kinase-2 and from native rat liver casein kinase-2 beta. European Journal of Biochemistry, Vol. 218, No. 2, (December 1), pp. 515-521, ISSN 0014-2956.

Boldyreff, B., Mietens, U., Issinger O.-G. (1996) Structure of protein kinase CK2: dimerization of the human beta-subunit. FEBS Letters, Vol. 379, No.2, (January 1996), pp. 153-156, ISSN 0014-5793.

Brognard, J. \& Hunter, T. (2011) Protein kinase signaling networks in cancer. Current Opinion in Genetics and Development, Vol. 21, No.1, (February 2011), pp. 4-11, ISSN 0959-437X.

Bosc, D. G., Slominski, E., Sichler, C. \& Litchfield, D. W. (1995). Phosphorylation of casein kinase II by p34cdc2. Identification of phosphorylation sites using phosphorylation site mutants in vitro. The Journal of Biological Chemistry, Vol. 270, No. 43, (October 1995), pp. 25872-25878, ISSN 0021-9258

Bossemeyer, D. (1994). The glycine-rich sequence of protein kinases: a multifunctional element. Trends in Biochemical Sciences, Vol. 19, No. 5, (May 1994), pp. 201-205, ISSN 0968-0004

Burnett, G. \& Kennedy E.P. (1954) The enzymatic phosphorylation of proteins. The Journal of Biological Chemistry, Vol. 211, No. 2, (December 1954), pp. 969-980, ISSN 0021-9258.

Canton, D.A., Zhang, C., Litchfield, D.W. (2001) Assembly of protein kinase CK2: investigation of complex formation between catalytic and regulatory subunits using a zinc-finger-deficient mutant of CK2beta. Biochemical Journal, Vol. 358, Pt. 1, (August 2001), pp. 87-94, ISSN 0264-6021.

Chantalat, L., Leroy, D., Filhol, O., Nueda, A., Benitez, M.J., Chambaz, E.M., Cochet, C., Dideberg, O. (1999) Crystal structure of the human protein kinase CK2 regulatory subunit reveals its zinc finger-mediated dimerization. The EMBO Journal, Vol. 18, No. 11, (June 1999), pp. 2930-2940, ISSN 0261-4189.

Chaillot, D., Declerck, N., Niefind, K., Schomburg, D., Chardot, T. \& Meunier, J.C. (2000). Mutation of recombinant catalytic subunit alpha of the protein kinase CK2 that affects catalytic efficiency and specificity. Protein Engineering, Vol. 13, No. 4, (April 2000), pp. 291-298, ISSN 0269-2139.

Chen, M., Li D., Krebs, E.G., Cooper, J.A. (1997) The casein kinase II beta subunit binds to Mos and inhibits Mos activity. Molecular and Cellular Biology, Vol. 17, No. 4, (April 1997), pp. 1904-1912, ISSN 0270-7306.

Coccetti, P., Rossi, R. L., Sternieri, F., Porro, D., Russo, G. L., di Fonzo, A., Magni, F., Vanoni, M. \& Alberghina, L. (2004). Mutations of the CK2 phosphorylation site of Sic1 affect cell size and S-Cdk kinase activity in Saccharomyces cerevisiae. Molecular Microbiology, Vol. 51, No. 2, (January 2004), pp. 447-460, ISSN 0950-382X. 
Coccetti, P., Zinzalla, V., Tedeschi, G., Russo, G. L., Fantinato, S., Marin, O., Pinna, L. A., Vanoni, M. \& Alberghina, L. (2006). Sic1 is phosphorylated by CK2 on Ser201 in budding yeast cells. Biochemical and Biophysical Research Communications, Vol. 346, No. 3, (August 2006), pp. 786-793, ISSN 0006-291X.

Cohen, P. (2002) Protein kinases - the major drug targets of the twenty-first century? Nature Reviews Drug Discovery, Vol. 1, No. 4, (April 2002), pp. 309-315, ISSN 1474-1776.

Cosmelli, D., Antonelli, M., Allende, C. C. \& Allende, J. E. (1997). An inactive mutant of the alpha subunit of protein kinase CK2 that traps the regulatory CK2beta subunit. FEBS letters, Vol. 410, No. 2-3, (June 1997), pp. 391-396, ISSN 0014-5793.

Cristiani, A., Costa, G., Cozza, G., Meggio, F., Scapozza, L. \& Moro, S. (2011). The role of the $\mathrm{N}$-terminal domain in the regulation of the "constitutively active" conformation of protein kinase CK2alpha: insight from a molecular dynamics investigation. ChemMedChem, Vol. 6, No. 7, (July 2011), pp. 1207-1216, ISSN 1860-7187.

Di Maira, G., Salvi, M., Arrigoni, G., Marin, O., Sarno, S., Brustolon, F., Pinna, L. A. \& Ruzzene, M. (2005). Protein kinase CK2 phosphorylates and upregulates Akt/PKB. Cell death and differentiation, Vol. 12, No. 6, (June 2005), pp. 668-677, ISSN 1350-9047.

Dobrowolska, G., Meggio, F., Marin, O., Lozeman, F. J., Li, D., Pinna, L. A. \& Krebs, E. G. (1994). Substrate recognition by casein kinase-II: the role of histidine-160. FEBS letters, Vol. 355, No. 3, (December 1994), pp. 237-241, ISSN 0014-5793.

Duncan J.S., Litchfield D.W. (2008) Too much of a good thing: The role of protein kinase CK2 in tumorigenesis and prospects for therapeutic inhibition of CK2. Biochemica et Biophysica Acta, Vol. 1784, No. 1, (January 2008), pp. 33-47, ISSN 0006-3002.

Duncan, J.S., Turowec, J.P., Vilk, G., Li, S.S.C., Gloor, G.B., Litchfield, D.W. (2010) Regulation of cell proliferation and survival: Convergence of protein kinases and caspases. Biochemica et Biophysica Acta, Vol. 1804, No. 3, (March 2010) pp. 505-510, ISSN 00063002.

Ermakova, I., Boldyreff, B., Issinger, O. G. \& Niefind, K. (2003). Crystal structure of a Cterminal deletion mutant of human protein kinase CK2 catalytic subunit. Journal of Molecular Biology, Vol. 330, No. 5, (July 2003), pp. 925-934, ISSN 0022-2836.

Faust, M., Montenarh, M. (2000) Subcellular localization of protein kinase CK2. A key to its function? Cell and Tissue Research, Vol. 301, No. 3, (September 2000), pp. 329-340, ISSN 0302-766X.

French, A. C., Luscher, B. \& Litchfield, D. W. (2007). Development of a stabilized form of the regulatory CK2beta subunit that inhibits cell proliferation. The Journal of Biological Chemistry, Vol. 282, No. 40, (October 2007), pp. 29667-29677, ISSN 0021-9258.

Gatica, M., Jedlicki, A., Allende, C. C. \& Allende, J. E. (1994). Activity of the E75E76 mutant of the alpha subunit of casein kinase II from Xenopus laevis. FEBS Letters, Vol. 339, No. 1-2, (February 1994), pp. 93-96, ISSN 0014-5793.

Ghosh \& Adams (2011) Phosphorylation mechanism and structure of serine-arginine protein kinases. The FEBS Journal, Vol. 278, No. 4, (February 2011), pp. 587-597, ISSN 17424658

Gianoncelli, A., Cozza, G., Orzeszko, A., Meggio, F., Kazimierczuk, Z., Pinna, L.A. (2009) Tetraiodobenzimidazoles are potnt inhibitors of protein kinase CK2. Bioorganic $\mathcal{E}$ Medicinal Chemistry, Vol. 17, No 20, (October 2009), pp. 7281-7289, ISSN 0968-0896. 
Gietz, R.D., Graham, K.C. and Litchfield, D.W. (1995) Interactions between the subunits of casein kinase II. The Jornal of Biological Chemistry, Vol. 270, No. 22, (June 1995), pp. 13017-13021. ISSN 0021-9258.

Glover C.V. (1998) On the physiological role of casein kinase II in Saccharomyces cerevisiae. Progress in Nucleic Acid Research \& Molecular Biology, Vol. 59, (May 1998), pp. 95133, ISSN 0079-6603.

Gotz, C., Kartarius, S., Scholtes, P., Nastainczyk, W. \& Montenarh, M. (1999). Identification of a CK2 phosphorylation site in mdm2. European Journal of biochemistry / FEBS, Vol. 266, No. 2, (December 1999), pp. 493-501, ISSN 0014-2956

Gotz, C., Scholtes, P., Prowald, A., Schuster, N., Nastainczyk, W. \& Montenarh, M. (1999). Protein kinase CK2 interacts with a multi-protein binding domain of p53. Molecular and Cellular Biochemistry, Vol. 191, No. 1-2, (January 1999), pp. 111-120, ISSN 03008177

Graham, K.C. and Litchfield, D.W. (2000) The regulatory beta subunit of protein kinase CK2 mediates formation of tetrameric CK2 complexes. J. Biol. Chem. 275: 5003-5010.

Grasselli, E., Tomati, V., Bernasconi, M. V., Nicolini, C. \& Vergani, L. (2004). C-terminal region of protein kinase CK2 alpha: How the structure can affect function and stability of the catalytic subunit. Journal of Cellular Bbiochemistry, Vol. 92, No. 2, (May 2004), pp. 270-284, ISSN 0730-2312

Guerra, B. (2006). Protein kinase CK2 subunits are positive regulators of AKT kinase. International Journal of Oncology, Vol. 28, No. 3, (March 2006), pp. 685-693, ISSN 1019-6439

Guerra B. \& Issinger O.-G. (2008) Protein kinase CK2 in human diseases. Current Medicinal Chemistry, Vol. 15, No. 19, pp. 1870-1886, ISSN 0929-8673.

Guerra B., Issinger O.-G., Wang J.Y. (2003) Modulation of human checkpoint kinase Chk1 by the regulatory beta-subunit of protein kinase CK2. Oncogene, Vol. 22, No. 32, (August 7), pp. 4933-4942, ISSN 0950-9232.

Guerra, B., Boldyreff, B., Sarno, S., Cesaro, L., Issinger, O. G. \& Pinna, L. A. (1999). CK2: a protein kinase in need of control. Pharmacology \& Therapeutics, Vol. 82, No. 2-3, (May-June 1999), pp. 303-313, ISSN 0163-7258.

Gyenis, L. \& Litchfield, D.W. (2008) The emerging CK2 interactome: insights into the regulation and functions of CK2. Molecular and Cellular Biochemistry, Vol. 316, No. 12, (September 2008), pp. 5-14, ISSN 0300-8177

Hanks, S. K. \& Hunter, T. (1995). Protein kinases 6. The eukaryotic protein kinase superfamily: kinase (catalytic) domain structure and classification. The FASEB Journal, Vol. 9, No. 8, (May 1995), pp. 576-596, ISSN 0892-6638.

Hanks, S.K., Quinn, A.M., Hunter, T. (1988) The protein kinase family: conserved features and deduced phylogeny of the catalytic domains. Science, Vol. 241, No. 4861 , (July 1), pp. 42-52, ISSN 0036-8075.

Hinrichs, M. V., Jedlicki, A., Tellez, R., Pongor, S., Gatica, M., Allende, C. C. \& Allende, J. E. (1993). Activity of recombinant alpha and beta subunits of casein kinase II from Xenopus laevis. Biochemistry, Vol. 32, No. 28, (July 1993), pp. 7310-7316, ISSN 00062960 
Hinrichs, M. V., Gatica, M., Allende, C. C. \& Allende, J. E. (1995). Site-directed mutants of the beta subunit of protein kinase CK2 demonstrate the important role of Pro-58. FEBS Letters, Vol. 368, No. 2, (July 1995), pp. 211-214, ISSN 0014-5793

$\mathrm{Hu}$, E. \& Rubin, C. S. (1990). Expression of wild-type and mutated forms of the catalytic (alpha) subunit of Caenorhabditis elegans casein kinase II in Escherichia coli. The Jornal of Biological Chemistry,, Vol. 265, No. 33, (November 1990), pp. 20609-20615, ISSN 0021-9258.

Issinger O.-G. (1993) Casein kinases: pleiotropic mediators of cellular regulation. Pharmacology \& Therapeutics, Vol. 59, No. 1, (January 1993), pp. 1-30, ISSN 01637258.

Jacob, G., Neckelman, G., Jimenez, M., Allende, C. C. \& Allende, J. E. (2000). Involvement of asparagine 118 in the nucleotide specificity of the catalytic subunit of protein kinase CK2. FEBS Letters, Vol. 466, No. 2-3, (January 2000), pp. 363-366, ISSN 0014-5793.

Jakobi, R. \& Traugh, J. A. (1992). Characterization of the phosphotransferase domain of casein kinase II by site-directed mutagenesis and expression in Escherichia coli. The Journal of Biological Chemistry, Vol. 267, No. 33, (November 1992), pp. 23894-23902, ISSN 0021-9258.

Jakobi, R., Lin, W. J. \& Traugh, J. A. (1994). Modes of regulation of casein kinase II. Cellular $\mathcal{E}$ Molecular Biology Research, Vol. 40, No. 5-6, pp. 421-429, ISSN 0968-8773.

Jakobi, R. \& Traugh, J. A. (1995). Site-directed mutagenesis and structure/function studies of casein kinase II correlate stimulation of activity by the beta subunit with changes in conformation and ATP/GTP utilization. European Journal of Biochemistry, Vol. 230, No. 3, (June 1995), pp. 1111-1117, ISSN 0014-2956

Janeczko, M., Masłyk, M., Szyszka, R., Baier, A. (2011) Interactions between subunits of protein kinase CK2 and their protein substrates influences its sensitivity to specific inhibitors. Molecular \& Cellular Biochemistry, Vol. 356, No. 1-2, (October 2011), pp. 121-126, ISSN 0300-8177.

Jauch, E., Melzig, J., Brkulj, M., Raabe, T. (2002) In vivo functional analysis of Drosophila protein kinase casein kinase 2 (CK2) beta-subunit. Gene, Vol. 298, No.1, (September 18), pp. 29-39, ISSN_0378-1119.

Jedlicki, A., Allende, C. C. \& Allende, J. E. (2008). CK2alpha/CK1alpha chimeras are sensitive to regulation by the CK2beta subunit. Molecular $\mathcal{E}$ Cellular Biochemistry, Vol. 316, No. 1-2, (September 2008), pp. 25-35, ISSN 0300-8177

Jensen, B.C., Kifer, C.T., Brekken, D.L., Randall A.C., Wang, Q., Drees, B.L. \& Parsons M. (2007) Characterization of protein kinase CK2 from Trypanosoma brucei. Molecular $\mathcal{E}$ Biochemical Parasitology, Vol. 151, No. 1, (January 2007), pp. 28-40, ISSN 0166-6851.

Johnson S.N. (2009) Protein kinase inhibitors: contributions from structure to clinical compounds. Quarterly Reviews of Biophysics, Vol. 42, No. 1, (February 2009), pp. 140, ISSN 0033-5835.

King, R.W., Glotzer, M., Kirschner, M.W. (1996) Mutagenic analysis of the destruction signal of mitotic cyclins and structural characterization of ubiquitinated intermediates. Molecular Biology of the Cell, Vol 7, No. 9, (September 1996), pp. 1343-1357, ISSN 1939-4586.

Knighton, D.R., Zheng, J.H., Ten Eyk, L.F., Ashford, V.A., Xuong, N.H., Taylor, S.S., Sowadski, J.M. (1991) Crystal structure of the catalytic subunit of cyclic adenosine 
monophosphate-dependent protein kinase. Science, Vol. 253, No. 5018, (July 1991), pp. 407-414, ISSN 0036-8075.

Kolaiti R.-M., Baier A., Szyszka R., Kouyanou-Koutsoukou S. (2011) Isolation of a CK2a subunit and the holoenzyme from the mussel Mytilus galloprovincialis and construction of the CK2 $\alpha$ and CK2 $\beta$ cDNAs. Marine Biotechnology (New York), Vol. 13, No. 3, (June 2011), pp. 505-516, ISSN 1436-2228.

Kopp, J., Schwede, T. (2004) Automated protein structure homology modeling: a progress report. Pharmacogenomics, Vol. 5, No. 4, (June 2004), pp. 405-416, ISSN 1462-2416.

Kouyanou-Koutsoukou S., Baier A., Kolaitis R.-M., Maniatopoulou E., Thanopoulou K., Szyszka R. (2011a) Cloning and purification of protein kinase CK2 recombinant alpha and beta subunits from the Mediterranean fly Ceratitis capitata. Molecular and Cellular Biochemistry, Vol. 356, No. 1-2, (October 2011), pp. 261-267, ISSN 0300-8177.

Kouyanou-Koutsoukou S., Kalpaxis D.L., Pytharopoulou S., Kolaitis R.-M., Baier A. and Szyszka R. (2011b) Translational control of gene expression in the mussel Mytilus galloprovincials: The impact of cellular stress on protein synthesis, the ribosomal stalk and the protein kinase CK2 activity. In: Mussels: Anatomy, Habitat and Environmental Impact. (Ed. Lauren E. McGevin), Nova Publisher, pp. 97-128, ISBN 97816176176381617617636.

Krehan, A., Lorenz, P., Plana-Coll, M. \& Pyerin, W. (1996). Interaction sites between catalytic and regulatory subunits in human protein kinase CK2 holoenzymes as indicated by chemical cross-linking and immunological investigations. Biochemistry, Vol. 35, No. 15, (April 1996), pp. 4966-4975, ISSN 0006-2960

Kristensen, L.P., Larsen, M.R., Højrup, P., Issinger, O.-G., Guerra, B. (2004) Phosphorylation of the regulatory $\beta$-subunit of protein kinase CK2 by checkpoint kinase Chk1: identification of the in vitro CK2 $\beta$ phosphorylation site. FEBS Letters, Vol.569, No. 13, (July 2004), pp. 217-223, ISSN 0014-5793.

Krupa, A., Abhinandan, K.R., Srinivasan, N. (2004) KinG: a database of protein kinases in genomes. Nucleic Acids Research, Vol. 32 (Database Issue), (January 2004), pp. D153D155, ISSN 0305-1048.

Kubiński, K., Domańska, K., Sajnaga, E., Mazur, E., Zieliński, R. \& Szyszka, R. (2007) Yeast holoenzyme of protein kinase CK2 requires both $\beta$ and $\beta^{\prime}$ regulatory subunits for its activity. Molecular \& Cellular Biochemistry, Vol. 295, No. 1-2, (January 2007), pp. 229-235, ISSN 0300-8177.

Kubler, D., Pyerin, W., Burow, E. \& Kinzel, V. (1983). Substrate-effected release of surfacelocated protein kinase from intact cells. Proceedings of the National Academy of Sciences of the United States of America, Vol. 80, No. 13, (July 1983), pp. 4021-4025, ISSN 0027-8424.

Kusk, M., Bendixen, C., Duno, M., Westergaard, O. \& Thomsen, B. (1995). Genetic dissection of intersubunit contacts within human protein kinase CK2. Journal of Molecular Biology, Vol. 253, No. 5, (November 1995), pp. 703-711, ISSN 0022-2836.

Lebrin, F., Chambaz, E. M. \& Bianchini, L. (2001). A role for protein kinase CK2 in cell proliferation: evidence using a kinase-inactive mutant of CK2 catalytic subunit alpha. Oncogene, Vol. 20, No. 16, (April 2001), pp. 2010-2022, ISSN 0950-9232.

Leroy, D., Alghisi, G.C., Roberts, E., Filhol-Cochet, O., Gasser, S.M. (1999) Mutations in the C-terminal domain of topoisomerase II affect meiotic function and interaction with 
the casein kinase 2 beta subunit. Molecular \& Cellular Biochemistry, Vol. 191, No. 1-2, (January 1999), pp. 85-95, ISSN 0300-8177.

Leroy, D., Heriche, J.K., Filhol, O., Chambaz, E.M. Cochet, C. (1997) Binding of polyamines to an autonomous domain of the regulatory subunit of protein kinase CK2 induces a conformational change in the holoenzyme. A proposed role for the kinase stimulation. The Journal of Biological Chemistry, Vol. 272, No. 33, (August 1997), pp. 20820-20827, ISSN 0021-9258.

Li, D., Dobrowolska, G., Aicher, L. D., Chen, M., Wright, J. H., Drueckes, P., Dunphy, E. L., Munar, E. S. \& Krebs, E. G. (1999). Expression of the casein kinase 2 subunits in Chinese hamster ovary and 3T3 L1 cells provides information on the role of the enzyme in cell proliferation and the cell cycle. The Journal of Biological Chemistry, Vol. 274, No. 46, (November 1999), pp. 32988-32996, ISSN 0021-9258

Li, D., Meier, U.T., Dobrowolska, G. \& Krebs E.G. (1997) Specific interaction between casein kinase 2 and the nucleolar protein Nopp140. The Journal of Biological Chemistry, Vol. 272, No. 6, (February 1997), pp. 3773-3779, ISSN 0021-9258

Lieberman, S.L. \& Ruderman, J.V. (2004) CK2 beta, which inhibits Mos function, binds to a discrete domain in the N-terminus of Mos. Developmental Biology, Vol. 268, No. 2, (April 2004), pp. 271-279, ISSN 0012-1606.

Liolli G., 2010. Structural dissection of cyclin dependent kinases regulation and protein recognition properties. Cell Cycle, Vol. 9, No. 8, (April 2010), pp. 1551-1561, ISSN $1538-4101$.

Litchfield, D. W. (2003). Protein kinase CK2: structure, regulation and role in cellular decisions of life and death. The Biochemical Journal, Vol. 369, Pt 1, (January 2003), pp. 1-15, ISSN 0264-6021

Litchfield, D.W., Bosc, D.G., Slonimski, E. (1995) The protein kinase from mitotic human cells that phosphorylates Ser-209 on the casein kinase II beta-subunit is p34cdc2. Biochemica et Biophysica Acta, Vol. 1269, No. 1, (October 1995), pp. 69-78, ISSN 00063002.

Litchfield, D.W., Lozeman, F.J., Piening, C., Sommercorn, J., Takio, K., Walsh, K.A. \& Krebs E.G. (1990) Subunit structure of casein kinase II from bovine testis: demonstration that the $\alpha$ and $\alpha^{\prime}$ subunits are distinct polypeptides. The Journal of Biological Chemistry, Vol. 265, No. 13, (May 1990), pp. 7638-7644, ISSN 0021-9258.

Luscher, B. \& Litchfield, D. W. (1994). Biosynthesis of casein kinase II in lymphoid cell lines. European Journal of Biochemistry, Vol. 220, No. 2, (March 1994), pp. 521-526, ISSN 0014-2956.

Manning G., Plowman G.D., Hunter T. \& Sudarsanam S. (2002a) Evolution of protein kinase signaling from yeast to man. Trends in Biochemical Sciences, Vol. 27, No. 10, (October 2002), pp. 514-520, ISSN 0968-0004

Manning, G., Whyte, D.B., Martinez, R., Hunter, T. \& Sudarsanam S. (2002b) The protein kinase complement of the human genome. Science, Vol. 298, No. 5600, (December 2002), pp. 1912-1934, ISSN 0036-8075.

Maridor G., Park W., Krek W. \& Nigg E.A. (1991) Casein kinase II. cDNA sequences, developmental expression and tissue distribution of mRNAs for $a$, $a^{\prime}$ and $b$ subunits of the chicken enzyme. The Journal of Biological Chemistry, Vol. 266, No. 4, (February 1991), pp. 2362-2368, ISSN 0021-9258. 
Marin, O., Meggio, F. \& Pinna, L.A. (1999) Structural features underlying the unusual mode of calmodulin phosphorylation by protein kinase CK2: A study with synthetic calmodulin fragments. Biochemical and Biophysical Research Communications, Vol. 256, No. 2, (March 1999), pp. 442-446, ISSN 0006-291X.

Miranda-Saavedra, D. \& Barton, G.J. (2007) Classification and functional annotation of eukaryotic protein kinases. Proteins, Vol. 68, No. 4, (September 2007), pp. 893-914, ISSN 0887-3585.

Marin, O., Meggio, F., Draetta, G. \& Pinna, L. A. (1992). The consensus sequences for cdc2 kinase and for casein kinase-2 are mutually incompatible. A study with peptides derived from the beta-subunit of casein kinase-2. FEBS Letters, Vol. 301, No. 1, (April 1992), pp. 111-114, ISSN 0014-5793.

Marin, O., Meggio, F., Boldyreff, B., Issinger, O. G. \& Pinna, L. A. (1995). Dissection of the dual function of the beta-subunit of protein kinase CK2 ('casein kinase-2'): a synthetic peptide reproducing the carboxyl-terminal domain mimicks the positive but not the negative effects of the whole protein. FEBS Letters, Vol. 363, No. 1-2, (April 1995), pp. 111-114, ISSN 0014-5793.

Marin, O., Meggio, F., Sarno, S. \& Pinna, L. A. (1997). Physical dissection of the structural elements responsible for regulatory properties and intersubunit interactions of protein kinase CK2 beta-subunit. Biochemistry, Vol. 36, No. 23, (June 1997), pp. $7192-$ 7198, ISSN 0006-2960.

Meggio, F., Boldyreff, B., Marin, O., Marchiori, F., Perich, J. W., Issinger, O. G. \& Pinna, L. A. (1992). The effect of polylysine on casein-kinase-2 activity is influenced by both the structure of the protein/peptide substrates and the subunit composition of the enzyme. European Journal of Biochemistry, Vol. 205, No. 3, (May 1992), pp. 939-945, ISSN 0014-2956.

Meggio, F., Boldyreff, B., Issinger, O. G. \& Pinna, L. A. (1993). The autophosphorylation and p34cdc2 phosphorylation sites of casein kinase-2 beta-subunit are not essential for reconstituting the fully-active heterotetrameric holoenzyme. Biochimica et Biophysica Acta, Vol. 1164, No. 2, (July 1993), pp. 223-225, ISSN 0006-3002.

Meggio, F., Boldyreff, B., Issinger, O. G. \& Pinna, L. A. (1994). Casein kinase 2 downregulation and activation by polybasic peptides are mediated by acidic residues in the 55-64 region of the beta-subunit. A study with calmodulin as phosphorylatable substrate. Biochemistry, Vol. 33, No. 14, (April 1994), pp. 4336-4342, ISSN 0006-2960.

Meggio, F. \& Pinna, L. A. (2003). One-thousand-and-one substrates of protein kinase CK2? The FASEB journal : official publication of the Federation of American Societies for Experimental Biology, Vol. 17, No. 3, (March 2003), pp. 349-368, ISSN 1530-6860

Messenger, M. M., Saulnier, R. B., Gilchrist, A. D., Diamond, P., Gorbsky, G. J. \& Litchfield, D. W. (2002). Interactions between protein kinase CK2 and Pin1. Evidence for phosphorylation-dependent interactions. The Journal of Biological Chemistry, Vol. 277, No. 25, (June 2002), pp. 23054-23064, ISSN 0021-9258

Miller, S. J., Lou, D. Y., Seldin, D. C., Lane, W. S. \& Neel, B. G. (2002). Direct identification of PTEN phosphorylation sites. FEBS letters, Vol. 528, No. 1-3, (September 2002), pp. 145-153, ISSN 0014-5793

Miravet, S., Piedra, J., Miro, F., Itarte, E., Garcia de Herreros, A. \& Dunach, M. (2002). The transcriptional factor Tcf- 4 contains different binding sites for beta-catenin and 
plakoglobin. The Journal of Biological Chemistry, Vol. 277, No. 3, (January 2002), pp. 1884-1891, ISSN 0021-9258

Nash, P., Tang, X., Orlicky, S., Chen, Q., Gertler, F. B., Mendenhall, M. D., Sicheri, F., Pawson, T. \& Tyers, M. (2001). Multisite phosphorylation of a CDK inhibitor sets a threshold for the onset of DNA replication. Nature, Vol. 414, No. 6863, (November 2001), pp. 514-521, ISSN 0028-0836.

Niefind, K., Guerra, B., Ermakowa, I. \& Issinger, O.-G. (2000). Crystallization and preliminary characterization of crystals of human protein kinase CK2. Acta Crystallographica. Section D, Biological Crystallography, Vol. 56, No. Pt 12, (December 2000), pp. 1680-1684, ISSN 0907-4449.

Niefind, K., Guerra, B., Ermakowa, I. \& Issinger, O.-G. (2001). Crystal structure of human protein kinase CK2: insights into basic properties of the CK2 holoenzyme. The EMBO journal, Vol. 20, No. 19, (October 2001), pp. 5320-5331, ISSN 0261-4189.

Niefind, K. \& Issinger, O. G. (2010). Conformational plasticity of the catalytic subunit of protein kinase CK2 and its consequences for regulation and drug design. Biochimica et Biophysica Acta, Vol. 1804, No. 3, (March 2010), pp. 484-492, ISSN 0006-3002.

Niefind K., Raaf J. \& Issinger O.-G. (2009) Protein kinase CK2 in health and disease: Protein kinase CK2: from structures to insights. Cellular and Molecular Life Sciences, Vol. 66, No. 11-12, (June 2009), pp. 1800-1816, ISSN 1420-682X.

Olsen, B. B., Guerra, B., Niefind, K. \& Issinger, O. G. (2010). Structural basis of the constitutive activity of protein kinase CK2. Methods in Enzymology, Vol. 484, No. pp. 515-529, ISSN 1557-7988.

Olsen, B. B. \& Guerra, B. (2008) Ability of CK2 $\beta$ to selectively regulate cellular protein kinases. Molecular \& Cellular Biochemistry, Vol. 316, No. 1-2, (September 2008), pp. 115-126, ISSN 0300-8177.

Olsten, M.E., Litchfield D.W., (2004) Order or chaos? An evaluation of the regulation of protein kinase CK2. Biochemistry \& Cell Biology, Vol. 82, No. 6, (December 2004), pp. 681-693, ISSN 0829-8211.

Olsten, M.E., Weber J.E., Litchfield D.W. (2005) CK2 interacting proteins: emerging paradigms for CK2 regulation? Molecular \& Cellular Biochemistry, Vol. 274, No. 1-2, (June 2005), pp. 115-124, ISSN 0300-8177.

Pagano, M.O., Bain, J., Kazimierczuk, Z., Sarno, S., Ruzzene, M., Di Maria, G., Elliott, M., Orzeszko, A., Cozza, G., Meggio, F. \& Pinna, L.A. (2008) The selectivity of inhibitors of protein kinase CK2: an update. Biochemical Journal, Vol. 415, No. 3, (November 2008), pp. 353-365, ISSN 0264-6021.

Pandit, S.B., Balaji, S., Srinivasan,N. (2004) Structural and functional characterization of gene products encoded in the human genome by homology detection. IUBMB Life, Vol. 56, No. 6, (June 2004), pp. 317-331, ISSN 1521-6543.

Pearson, M.A. \& Fabbro, D. (2004) Targetting protein kinases in cancer therapy: a success? Expert Review of Anticancer Therapy, Vol. 4, No.6., (December 2004), pp. 1113-1124, ISSN 1473-7140.

Pinna, L. A. (2002). Protein kinase CK2: a challenge to canons. Journal of Cell Science, Vol. 115, Pt. 20, (October 2002), pp. 3873-3878, ISSN 0021-9533 
Pinna, L. A. \& Meggio, F. (1997). Protein kinase CK2 ("casein kinase-2") and its implication in cell division and proliferation. Progress in Cell Cycle Research, Vol. 3, No. pp. 7797, ISSN 1087-2957

Plowman, G.D., Sudarsanam, S., Bingham, J., Whyte, D., Hunter, T., (1999) The protein kinases of Caenorhabditis elegans, a model for signal transduction in multicellular organisms. Proceedings of the National Academy of Sciences of the United States of America, Vol. 96, No. 24, (November 1999), pp. 13603-13610, ISSN 0027-8424.

Ponce, D., Maturana, J. L., Cabello, P., Yefi, R., Niechi, I., Silva, E., Armisen, R., Galindo, M., Antonelli, M. \& Tapia, J. C. (2011). Phosphorylation of AKT/PKB by CK2 is necessary for the AKT-dependent up-regulation of beta-catenin transcriptional activity. Journal of Cellular Physiology, Vol.226, No. 7, (July 2010), pp. 1953-1959, ISSN 1097-4652

Prudent, R., Sautel, C.F., Cochet, C. (2010) Structure-based discovery of small molecules targeting different surfaces of protein-kinase CK2. Biochimica et Biophysica Acta, Vol. 1804, No. 3, (March 2010), pp. 493-498, ISSN 0006-3002.

Raaf, J., Bischoff, N., Klopffleisch, K., Brunstein, E., Olsen, B. B., Vilk, G., Litchfield, D. W., Issinger, O.-G. \& Niefind, K. (2011) Interaction between CK2alpha and CK2beta, the subunits of protein kinase CK2: thermodynamic contributions of key residues on the CK2alpha surface. Biochemistry, Vol. 50, No. 4, (February 2011), pp. 512-522, ISSN 1520-4995.

Raaf, J., Brunstein, E., Issinger, O.-G., Niefind, K. (2008) The interaction of CK2alpha and CK2beta, the subunits of protein kinase CK2, requires CK2beta in a preformed conformation and is enthalpically driven. Protein Science, Vol. 17, No. 12, (December 2008), pp. 2180-2186, ISSN 0961-8368.

Riera, M., Peracchia, G., de Nadal, E., Ariño, J., Pagès, M. (2001) Maize protein kinase CK2: regulation and functionality of three beta regulatory subunits. The Plant Journal, Vol. 25, No. 4, (February 2001), pp. 365-374, ISSN 0960-7412.

Rodriguez, F. A., Contreras, C., Bolanos-Garcia, V. \& Allende, J. E. (2008). Protein kinase CK2 as an ectokinase: the role of the regulatory CK2beta subunit. Proceedings of the National Academy of Sciences of the United States of America, Vol. 105, No. 15, (April 2008), pp. 5693-5698, ISSN 1091-6490

Roussou, I, Draetta, G. (1994) The Schizosaccharomyces pombe casein kinase II alpha and beta subunits: evolutionary conservation and positive role of the beta subunit. Molecular and Cellular Biology, Vol. 14, No. 1, (January 1994), pp. 576-586, ISSN 0270-7306.

Sajnaga, E., Kubiński, K. \& Szyszka, R. (2008). Catalytic activity of mutants of yeast protein kinase CK2alpha. Acta Biochimica Polonica, Vol. 55, No. 4, (November 2008), pp. 767776, ISSN 0001-527X.

Salamon, J. A., Acuna, R. \& Dawe, A. L. (2010). Phosphorylation of phosducin-like protein BDM-1 by protein kinase 2 (CK2) is required for virulence and $\mathrm{G}$ beta subunit stability in the fungal plant pathogen Cryphonectria parasitica. Molecular Microbiology, Vol. 76, No. 4, (May 2010), pp. 848-860, ISSN 1365-2958.

Sarno, S., Boldyreff, B., Marin, O., Guerra, B., Meggio, F., Issinger, O.-G. \& Pinna, L. A. (1995). Mapping the residues of protein kinase CK2 implicated in substrate recognition: mutagenesis of conserved basic residues in the alpha-subunit. 
Biochemical and Biophysical Research Communications, Vol. 206, No. 1, (January 1995), pp. 171-179, ISSN 0006-291X

Sarno, S., Ghisellini, P., Cesaro, L., Battistutta, R. \& Pinna, L.A. (2001). Generation of mutants of CK2alpha which are dependent on the beta-subunit for catalytic activity. Molecular \& Cellular Biochemistry, Vol. 227, No. 1-2, (November 2001), pp. 13-19, ISSN 0300-8177.

Sarno, S., Ghisellini, P. \& Pinna, L.A. (2002). Unique activation mechanism of protein kinase CK2. The N-terminal segment is essential for constitutive activity of the catalytic subunit but not of the holoenzyme. The Journal of Biological Chemistry, Vol. 277, No. 25, (June 2002), pp. 22509-22514, ISSN 0021-9258.

Sarno, S., Marin, O., Boschetti, M., Pagano, M.A., Meggio, F., Pinna, L.A. (2000) Cooperative modulation of protein kinase CK2 by separate domains of its regulatory betasubunit. Biochemistry, Vol. 39, No.40, (October 10), pp. 12324-12329, ISSN 0006-2960.

Sarno, S., Ruzzene, M., Frascella, P., Pagano, M. A., Meggio, F., Zambon, A., Mazzorana, M., Di Maira, G., Lucchini, V. \& Pinna, L. A. (2005). Development and exploitation of CK2 inhibitors. Molecular \& Cellular Biochemistry, Vol. 274, No. 1-2, (June 2005), pp. 69-76, ISSN 0300-8177.

Sarno, S., Salvi, M., Battistutta, R., Zanotti, G. \& Pinna, L.A. (2005). Features and potentials of ATP-site directed CK2 inhibitors. Biochimica et Biophysica Acta, Vol. 1754, No. 1-2, (December 2005), pp. 263-270, ISSN 0006-3002.

Sarno, S., Vaglio, P., Cesaro, L., Marin, O. \& Pinna, L.A. (1999). A multifunctional network of basic residues confers unique properties to protein kinase CK2. Molecular \& Cellular Biochemistry, Vol. 191, No. 1-2, (January 1999), pp. 13-19, ISSN 0300-8177.

Sarno, S., Vaglio, P., Marin, O., Meggio, F., Issinger, O.-G. \& Pinna, L.A. (1997a). Basic residues in the 74-83 and 191-198 segments of protein kinase CK2 catalytic subunit are implicated in negative but not in positive regulation by the beta-subunit. European Journal of Biochemistry, Vol. 248, No. 2, (September 1997), pp. 290-295, ISSN 0014-2956.

Sarno, S., Vaglio, P., Marin, O., Issinger, O. G., Ruffato, K. \& Pinna, L.A. (1997b). Mutational analysis of residues implicated in the interaction between protein kinase CK2 and peptide substrates. Biochemistry, Vol. 36, No. 39, (September 1997), pp. 11717-11724, ISSN 0006-2960.

Sarno, S., Vaglio, P., Meggio, F., Issinger, O. G. \& Pinna, L. A. (1996). Protein kinase CK2 mutants defective in substrate recognition. Purification and kinetic analysis. The Journal of Biological Chemistry, Vol. 271, No. 18, (May 1996), pp. 10595-10601, ISSN 0021-9258.

Seldin, D. C., Landesman-Bollag, E., Farago, M., Currier, N., Lou, D. \& Dominguez, I. (2005). CK2 as a positive regulator of Wnt signalling and tumourigenesis. Molecular $\mathcal{E}$ Cellular Biochemistry, Vol. 274, No. 1-2, (June 2005), pp. 63-67, ISSN 0300-8177.

Shi, X., Potvin, B., Huang, T., Hilgard, P., Spray, D.C., Suadicani, S.O., Wolkoff, A.W., Stanley, P. and Stockert, R.J. (2001) A novel casein kinase 2 alpha-subunit regulates membrane protein traffic in the human hepatoma cell line HuH-7. The Journal of Biological Chemistry, Vol. 276, No. 3, (January 2001), pp. 2075-2082, ISSN 0021-9258 276: 2075-2082. 
Song, D. H., Dominguez, I., Mizuno, J., Kaut, M., Mohr, S. C. \& Seldin, D. C. (2003). CK2 phosphorylation of the armadillo repeat region of beta-catenin potentiates Wnt signaling. The Journal of Biological Chemistry, Vol. 278, No. 26, (June 2003), pp. 2401824025, ISSN 0021-9258.

Srinivasan, N., Antonelli, M., Jacob, G., Korn, I., Romero, F., Jedlicki, A., Dhanaraj, V., Sayed, M. F., Blundell, T. L., Allende, C. C. \& Allende, J. E. (1999). Structural interpretation of site-directed mutagenesis and specificity of the catalytic subunit of protein kinase CK2 using comparative modelling. Protein Engineering, Vol. 12, No. 2, (February 1999), pp. 119-127, ISSN 0269-2139.

St-Denis, N.A., Derksen, D.R. \& Litchfield, D.W. (2009) Evidence for regulation of mitotic progression through temporal phosphorylation and dephosphorylation of CK2alpha. Molecular \& Cellular Biology, Vol. 29, No. 8, (April), pp. 2068-2081, ISSN 0270-7306.

Trembley J.H., Wang G., Unger G., Slaton J. \& Ahmed K. (2009) CK2: a key player in cancer biology. Cellular and Molecular Life Sciences, Vol. 66, No 11-12, (June 2009), pp. 18581867, ISSN 1420-682X.

Tuazon, P. T. \& Traugh, J. A. (1991). Casein kinase I and II--multipotential serine protein kinases: structure, function, and regulation. Advances in Second Messenger and Phosphoprotein Research, Vol. 23, No. (January 1991), pp. 123-164, ISSN 1040-7952.

Vaglio, P., Sarno, S., Marin, O., Meggio, F., Issinger, O. G. \& Pinna, L. A. (1996). Mapping the residues of protein kinase CK2 alpha subunit responsible for responsiveness to polyanionic inhibitors. FEBS letters, Vol. 380, No. 1-2, (February 1996), pp. 25-28, ISSN 0014-5793.

Verma, R., McDonald, H., Yates, J. R., 3rd \& Deshaies, R. J. (2001). Selective degradation of ubiquitinated Sic1 by purified 26S proteasome yields active $S$ phase cyclin-Cdk. Molecular Cell, Vol. 8, No. 2, (August 2001), pp. 439-448, ISSN 1097-2765.

Vilk, G., Derksen, D. R. \& Litchfield, D. W. (2001). Inducible expression of the regulatory protein kinase CK2beta subunit: incorporation into complexes with catalytic CK2 subunits and re-examination of the effects of CK2beta on cell proliferation. Journal of Cellular Biochemistry, Vol. 84, No. 1, pp. 84-99, ISSN 0730-2312.

Vilk G., Weber J.E., Turowiec J.P., Duncan J.S., Wu C., Derksen D.R., Zień P., Sarno S., Donella-Deana A., Lajoie G., Pinna L.A., Li S.S. and Litchfield D.W. (2008) Protein kinase CK2 catalyzes tyrosine phosphorylation in mammalian cells. Cellular Signalling, Vol. 20, No. 11, (November 2008), pp. 1942-1951, ISSN 0898-6568.

Wirkner, U., Voss, H., Lichter, P., Pyerin, W. (1994) Human protein kinase CK2 genes. Cellular \& Molecular Biology Research, Vol. 40, No. 5-6, pp 489-99., ISSN 0968-8773.

Yde, C. W., Ermakova, I., Issinger, O. G. \& Niefind, K. (2005). Inclining the purine base binding plane in protein kinase CK2 by exchanging the flanking side-chains generates a preference for ATP as a cosubstrate. Journal of Molecular Biology, Vol. 347, No. 2, (March 2005), pp. 399-414, ISSN 0022-2836

Zhang, C., Vilk, G., Canton, D. A. \& Litchfield, D. W. (2002). Phosphorylation regulates the stability of the regulatory CK2beta subunit. Oncogene, Vol. 21, No. 23, (May 2002), pp. 3754-3764, ISSN 0950-9232 
Zhang, N. \& Zhong, R. (2010). Structural basis for decreased affinity of Emodin binding to Val66-mutated human CK2 alpha as determined by molecular dynamics. Journal of Molecular Modeling, Vol. 16, No. 4, (April 2010), pp. 771-780, ISSN 0948-5023

Zhang, Y. \& Dong, C. (2007) Regulatory mechanisms of mitogen-activated kinase signaling. Cellular \& Molecular Life Sciences, Vol. 64, No. 21, (November 2007), pp. 2771-2789, ISSN 1420-682X. 